\title{
Estudio arqueometalúrgico de un taller de transformación de cobre y de aleaciones tumbaga en el sitio de huacas de Moche
}

Étude archéometallurgique d'un atelier de transformation de cuivre et d'alliages tumbaga du site huacas Moche

Archaeometallurgical study of a copper and tumbaga alloy workshop at the site of Huacas de Moche

\section{Carole Fraresso}

\section{(2) OpenEdition}

\section{Journals}

Edición electrónica

URL: http://journals.openedition.org/bifea/2001

DOI: $10.4000 /$ bifea.2001

ISSN: 2076-5827

Editor

Institut Français d'Études Andines

Edición impresa

Fecha de publicación: 1 agosto 2010

Paginación: 351-387

ISSN: 0303-7495

Referencia electrónica

Carole Fraresso, «Estudio arqueometalúrgico de un taller de transformación de cobre y de aleaciones tumbaga en el sitio de huacas de Moche », Bulletin de l'Institut français d'études andines [En línea], 39

(2) | 2010, Publicado el 01 febrero 2011, consultado el 07 noviembre 2020. URL : http:// journals.openedition.org/bifea/2001 ; DOI : https://doi.org/10.4000/bifea.2001

\section{(2) $(\mathbb{\theta} \Theta \Theta$}

Les contenus du Bulletin de l'Institut français d'études andines sont mis à disposition selon les termes de la licence Creative Commons Attribution - Pas d'Utilisation Commerciale - Pas de Modification 4.0 International. 


\title{
Estudio arqueometalúrgico de un taller de transformación de cobre y de aleaciones tumbaga en el sitio de huacas de Moche
}

\author{
Carole Fraresso*
}

\begin{abstract}
Resumen
La excavación arqueológica del Centro Urbano mochica, localizado entre los templos monumentales de la huaca de la Luna y la huaca del Sol se inició en 1995 con el fin de mejorar el entendimiento de la organización sociopolítica y económica del fenómeno cultural Mochica (150-850d. C), en la costa norte del Perú. Los resultados, basados en el estudio de vestigios en cerámica, textiles y piedras semipreciosas registrados en varios talleres, han mostrado que diferentes actividades de producción especializada, para la fabricación de los objetos suntuarios que se utilizaban en las ceremonias del sitio, estaban controladas por los miembros de la elite local. En 2003, la excavación de un taller metalúrgico, localizado en el complejo residencial CA-27, brindó la oportunidad de examinar, desde un punto de vista arqueológico y tecnológico, los materiales y los procesos que eran empleados por un grupo de artesanos de la huaca de la Luna.

El estudio de los vestigios materiales consistía, en primer lugar, en identificar por medio de exámenes visuales los diferentes tipos de «desechos» y las estructuras. Luego, se realizó el estudio tecnológico de varios tipos de vestigios metálicos (lingotes, caídas de metal, barras planas, fragmentos de varillas, fallas de fabricación, etc.) y de artefactos no metálicos (fragmentos de crisoles, escorias de fusión, toberas de arcilla, etc.) por medio de exámenes metalográficos de probetas observadas en sección. Las composiciones químicas han sido obtenidas con un sistema de análisis en dispersión de energía de rayos X (EDXS) acoplado al microscopio electrónico de barrido.

Los resultados permiten discutir nuevos datos directamente ligados a la organización local de un taller metalúrgico. Además permiten caracterizar las aleaciones, procesos, técnicas de dorado y «cadenas operativas» que empleaban los artesanos de la capital de la región Mochica Sur, entre aproximadamente 600 y 700 d.C.
\end{abstract}

Palabras clave: metal, tumbaga, Mochica, estudio tecnológico, taller, producción artesanal, arqueometalurgia

Institut de Recherche sur les Archéomatériaux IRAMAT-CRP2A UMR5060-CNRS. Université Michel de Montaigne de Bordeaux 3, Instituto Francés de Estudios Andinos, Lima. 


\title{
Étude archéometallurgique d'un atelier de transformation de cuivre et d'alliages tumbaga du site huacas Moche
}

\section{Résumé}

La fouille archéologique du Centre Urbain Mochica, qui se trouve entre les temples monumentaux de la huaca de la Luna et de la huaca del Sol, a été entreprise en 1995 afin de mieux comprendre l'organisation socio-politique et économique du phénomène culturel Mochica (150-850 ap. J.-C.), sur la côte nord du Pérou. Les résultats, qui se fondent sur les vestiges de céramiques, de textiles et de pierres semi-précieuses mis au jour dans plusieurs ateliers, ont montré que différentes activités de production spécialisée étaient sous le contrôle des membres de l'élite locale pour répondre aux besoins matériels des cérémonies qui avaient lieu dans ces temples. En 2003, la fouille d'un atelier métallurgique, localisé dans le complexe résidentiel CA-27, a permis d'examiner, d'un point de vue archéologique et technologique, les matériaux et les procédés qui étaient utilisés par un groupe d'artisans de la huaca de la Luna.

L'étude des vestiges matériels a d'abord consisté à identifier, par des examens visuels, les différents types de « déchets » et les structures. S'en suivit l'étude technologique de plusieurs types de vestiges métalliques (lingots, chutes de métal, barres planes, fragments de tiges, ratés de fabrication, etc.) et d'artefacts non métalliques (fragments de creusets, scories de fusion, tuyères en argile, etc.) par des examens métallographiques en section. Les compositions chimiques ont été obtenues avec un système d'analyse en dispersion d'énergie de rayons X (EDXS) couplé à un microscope électronique à balayage (MEB).

Les résultats obtenus livrent un éclairage nouveau sur l'organisation locale d'un atelier métallurgique. De plus, ils permettent de caractériser les alliages cuivreux, les procédés, les techniques de dorure et les « chaînes opératoires » qu'employaient les artisans de la capitale de la région Mochica Sud, vers 600-700 ap. J.-C.

Mots clés: métal, tumbaga, Mochica, étude technologique, atelier, production artisanale, archéometallurgie

\section{Archaeometallurgical study of a copper and tumbaga alloy workshop at the site of Huacas de Moche}

\begin{abstract}
The archaeological excavation of the Moche urban centre, located between the monumental temples called Huaca de la Luna and Huaca del Sol, began in 1995 to get a better understanding of the social, economic and political Moche Culture phenomena of the northern coast of Peru (150-850 AD.). The results based on ceramic, textile and semiprecious stones remains, found in craftsmen workshops, establish that different activities of specialized production were controlled by elite people to provide the ceremonial services of both temples. In 2003, the archaeological excavation of a metallurgical workshop, located in the residential complex CA-27, created the opportunity to examine, from the archaeological and technological point of view, the workshop manufacturing processes used by a Huaca de la Luna craftsmen group.

The study of the materials remains firstly consists of identifying, by external observation, the different types of remains and structures. Secondly, we proceed to the technological study of selected metallic artifacts (ingots, sheets off-cut, flat bars and rods fragments, spoilt objects, etc.) and non-metallic artifacts (crucibles fragments, smelting slag, clay tuyeres, etc.) by metallographic examinations crosssection samples. Chemical compositions were obtained with an EDXS analysis system associated to a Scanning Electron Microscope.Some results obtained make it possible to discuss the new data's implications regarding local metallurgical workshop organization. Furthermore, they permit us to characterize base copper alloys, processes, gilding techniques and "operating chain(s)" that were employed by the craftsmen of the Moche southern capital, between 600 and 700 A.D.
\end{abstract}


Key words: Metal, tumbaga, Mochica, technological study, metal workshop, craft production, archaeometallurgy

\section{INTRODUCCIÓN}

Las excavaciones arqueológicas llevadas a cabo durante los veinte últimos años en los principales sitios mochicas de la costa norte del Perú, y el descubrimiento de varias tumbas «reales», en Dos Cabezas, El Brujo, Sipán, San José de Moro, Pacatnamú, huaca del Pueblo y la huaca de la Luna indican claramente el uso recurrente de numerosos adornos de metal en cobre y aleaciones preciosas de calidades, estética y técnica muy notorias, entre 150 et 650 a. C. Los estudios iconográficos y estilísticos han demostrado que los adornos suntuarios y objetos ceremoniales de metal, principalmente descubiertos en contextos funerarios y rituales, eran esencialmente fabricados para plasmar la identidad social de los actores políticos de esta importante sociedad del antiguo Perú. La función de los adornos de metal no era solamente estética sino más bien un medio de expresión, para esta sociedad sin escritura, para justificar, comunicar y vehicular los mitos y los símbolos de los diferentes poderes dominantes.

Sin embargo, hasta la fecha, muy pocos sitios o espacios de producción vinculados a las actividades del metal son conocidos para los periodos de la cultura Mochica. En el presente artículo, examinamos un espacio donde se llevaban a cabo actividades metalúrgicas para la fabricación de objetos singulares que eran probablemente directamente relacionados con las ceremonias y rituales que se realizaban en los templos de la capital Mochica.

El objetivo de este trabajo es doble1. En primer lugar, se trata de realizar una primera caracterización de los materiales, dispositivos y procesos que entran en la o las «cadena(s) operativa(s)» de fabricación del taller metalúrgico de la huaca de la Luna para responder a ciertas preguntas específicas: ¿Qué metal(es) y/o aleación(es) trabajaban los metalurgistas mochicas en este taller? ¿Recurrían a la fundición? Y si lo fuera, ¿Cómo y con qué tipo de dispositivos (hornos, sistema de ventilación), de herramientas (moldes, crisoles, etc.) y procesos? ¿Cuáles fueron las técnicas de fabricación utilizadas? ¿Recurrían a técnicas de deformación? En fin, ¿qué tipo(s) de pieza(s) eran manufacturadas en este taller?

En segundo lugar, pretendemos mejorar nuestra comprensión acerca de la organización del mundo artesanal de la sociedad Mochica. En efecto, comprender la organización espacial en barrios artesanales, los fenómenos de concurrencia o de complementariedad de la producción entre diferentes unidades o acercarse al rol y la posición social de los artesanos del metal son aspectos determinantes en

1 Este estudio entra en el marco más amplio de un trabajo de tesis doctoral llevado a cabo en cooperación con el Proyecto Arqueológico Huaca de la Luna-UNT, el Instituto Francés de Estudios Andinos-IFEA y la Universidad Michel de Montaigne de Burdeos 3, Francia (Fraresso, 2007). 
la definición de los sistemas económico, técnico, social y político que estructuran esta compleja sociedad.

\section{EL TALLER METALÚRGICO DEL COMPLEJO RESIDENCIAL CA-27}

\section{1. Localización y descripción}

Los trabajos de investigación llevados a cabo por los arqueólogos, tanto durante las excavaciones del Núcleo Urbano como en el templo de la huaca de la Luna, indican que la población residente en este lugar incluía, además de dirigentes de las esferas religiosas y administrativas, habitantes de clase media, cuyo estatus variaba seguramente en función de las actividades y de las responsabilidades empeñadas en cada sector: económico, administrativo y artesanal (Uceda, 2004b).

La organización urbana (canales de abastecimiento de agua, vías de circulación, plazas públicas, residencias administrativas) y el desarrollo de las actividades artesanales en la ciudad, durante las fases III y IV del sitio, es decir entre 400 y 900 d. C., parecen corresponder a una evolución neta de la división del trabajo y una organización corporativa en la cual ciertos especialistas eran directamente implicados en la producción de bienes de lujo (Canziani, 2003). Estos especialistas trabajaban en un ámbito necesariamente estructurado en el cual sus tareas eran controladas por y para la élite.

Durante la excavación arqueológica del complejo arquitectónico 27 (fig. 1), en 2003, los arqueólogos localizaron en el subconjunto 32, dos espacios (27-15 y 27-30), de $67 \mathrm{~m}^{2}$ y $55 \mathrm{~m}^{2}$, donde se registraron evidencias directas de actividades metalúrgicas del cobre y/o de aleación(es) de cobre. Los diversos vestigios materiales encontrados en el taller eran asociados a la capa de ocupación 2 (penúltima) que corresponde a la fase IV de Larco, es decir entre 600 y 700 d. C. (fig. 2).

El ambiente 27-30, que sufrió modificaciones formales y funcionales a manera de ampliaciones, consta de una pieza principal que está delimitada, al oeste, por un acceso directo al Callejón Sur 27 y, al este, por una serie de pequeños depósitos (27-25, 27-27, 27-28 y 27-29) (Chiguala et al., 2003: 112). Varios vestigios materiales metálicos (fragmentos de láminas, varillas y barras, masas de metal, gotas y salpicaduras de metal, zona de sales de cobre en el suelo) asociados a vestigios cerámicos (fragmentos de crisoles con restos de metal adherido en vitrificaciones, pequeñas toberas) y vestigios líticos (yunque, percutores y pulidores), fueron registrados directamente sobre el piso y el relleno asociados a la capa 2 del espacio 27-30 (Chiguala et al., 2003; Rengifo \& Rojas, 2004). Notamos la similitud de ciertos vestigios encontrados en el espacio 27-15, localizado al norte del taller 27-30. Sin embargo, el mal estado de conservación, resultante de la huaquería, así como la falta de vestigios en contextos primarios, no nos permiten determinar la función artesanal exacta de este espacio. 
Huacas de Moche: estudio arqueométrico de un taller de transformación de cobre

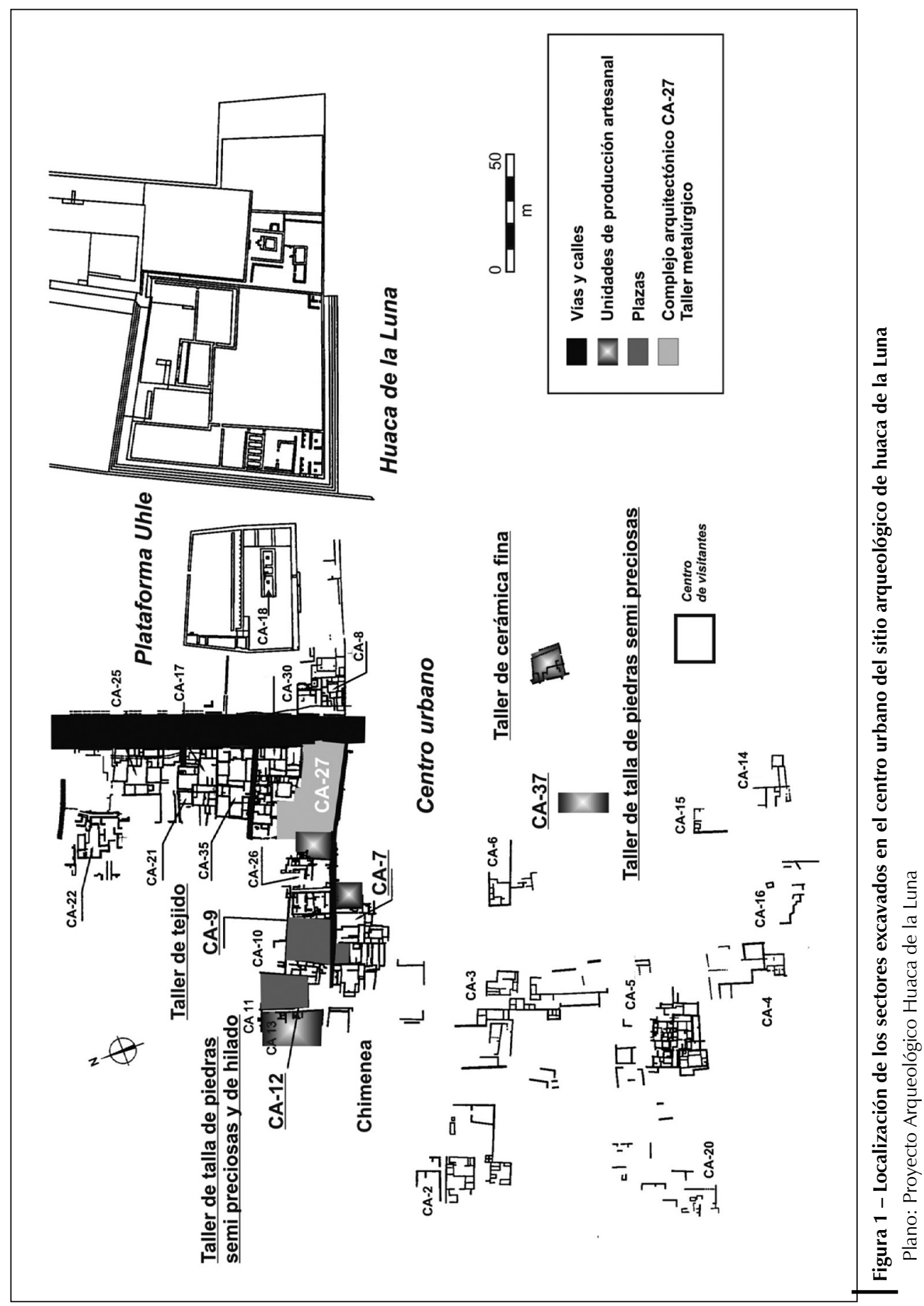




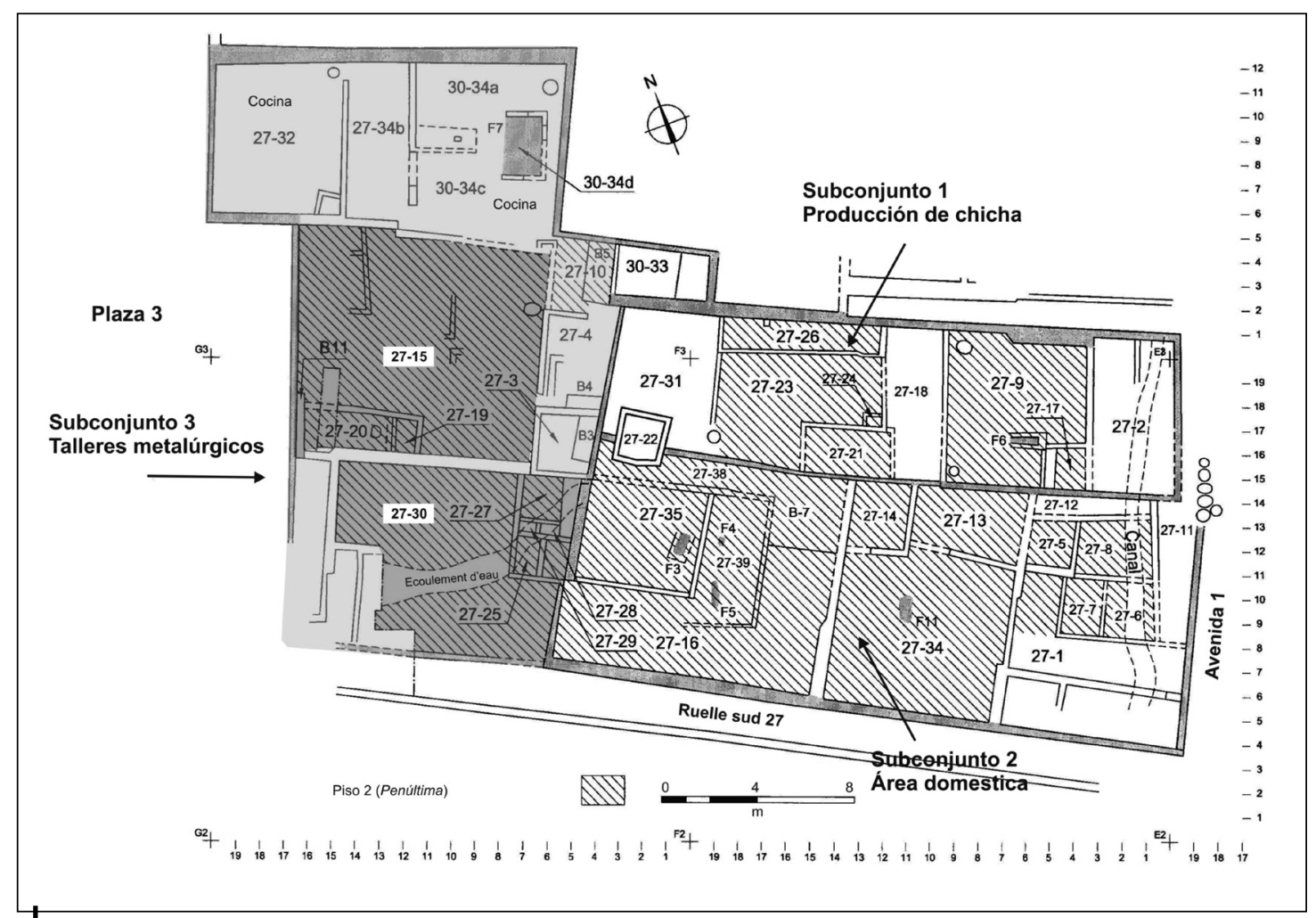

Figura 2 - Complejo residencial CA-27

Localización de los espacios 27-15 y 27-30 en el subconjunto 3 donde se registraron diferentes categorías de vestigios materiales relacionados con actividades metalúrgicas (Plano: Proyecto Arqueológico Huaca de la Luna)

\section{2. Testigos materiales de actividades metalúrgicas}

Un total de 467 fragmentos y elementos metálicos, 92 fragmentos de crisoles con restos de productos de corrosión de cobre, fragmentos de tiestos de cerámica gruesa con metal vitrificado y 27 pequeñas toberas rectas con extremo redondeado se encontraron en el subconjunto 3 del complejo CA-27. Con el fin de comprender la organización del trabajo en el taller metalúrgico, convenía, en un primer tiempo, localizar e identificar el material metálico, cerámico y lítico presente en los ambientes 27-30 y 27-15 del subconjunto 3. La totalidad de los vestigios ha sido observada y registrada en una base de datos para intentar determinar su función y luego proceder a la selección del muestreo. El material estudiado en el presente trabajo procede del contexto primario de la capa 2 y del 
relleno asociado específicamente al espacio 27-30 (fig. 3a). Sin embargo, algunos objetos directamente asociados al piso 2 del espacio 27-15 fueron también seleccionados con el fin de realizar comparaciones.

Los primeros exámenes han permitido distinguir que estos vestigios resultaban de actividades metalúrgicas asociadas a un taller de transformación del metal, es decir donde se transformaba el metal para fabricar objetos. Recordamos que las actividades metalúrgicas ligadas a la elaboración del metal, es decir a la obtención del metal a partir de un mineral, no se llevan a cabo en el mismo sitio y no son realizadas por los mismos hombres. Generalmente, un taller de elaboración produce materias primas que serán luego trabajadas en otro sitio, en un taller de transformación (Shimada, 1994: 202-203; Pernot, 2002: 123).

\section{METODOLOGÍA ANALÍTICA}

El estudio tecnológico consiste en realizar un examen metalográfico de muestras pulidas, previamente realizadas en objetos seleccionados a partir de las preguntas definidas. A continuación, se realizan análisis de composición elemental con el fin de caracterizar los materiales considerados³.

Debido a las malas condiciones de preservación del material metálico (sin resistencia mecánica/sin metal sano), el muestreo se restringió a 15 piezas metálicas y las muestras realizadas son de pequeño tamaño ${ }^{4}$ (unos cuantos $\mathrm{mm}^{3}$ ). Una preparación larga y meticulosa es necesaria para realizar los exámenes y los análisis. Cada muestra ha sido engastada en una resina sintética, la cual se coloca de tal manera que las observaciones se realizan en el plan direccional elegido: longitudinal y/o transversal. Las muestras, así preparadas, recibieron luego un cuidadoso proceso de pulido con diferentes pastas y papeles abrasivos de granulometría cada vez más fina, de $50 \mu \mathrm{m}$ a $0,25 \mu \mathrm{m}$.

Observaciones microscópicas de las muestras pulidas permiten caracterizar las diferentes inclusiones (óxidos, plomo y sulfuros) presentes en el metal o la aleación (Pernot \& Hurtel, 1987). Luego, las observaciones microscópicas de las muestras atacadas químicamente con una solución ácida ${ }^{5}$ permiten revelar la microestructura granular del metal (o de la aleación) y obtener informaciones acerca de la historia termomecánica del material, es decir sobre los últimos procesos de fabricación - mecánicos y/o térmicos- aplicados a la zona del objeto observada (Pernot, 1999: 66).

3 Los análisis físico químicos fueron realizados en el laboratorio del Institut de Recherche sur les Archéomatériaux IRAMAT-CRP2A UMR 5060-CNRS. Université Michel de Montaigne de Bordeos.

4 El muestreo ha sido efectuado con una sierra de orfebre.

5 Percloruro férrico alcohólico: mezcla de $20 \mathrm{ml}$ de cloruro férrico $\left(\mathrm{FeCl}_{3}, \mathrm{~d}=1,26\right), 2 \mathrm{ml}$ de acido clorhídrico $(\mathrm{HCl}, \mathrm{d}=1,18)$ y $96 \mathrm{ml}$ de etanol $\left(\mathrm{C}_{2} \mathrm{H}_{5} \mathrm{OH}, \mathrm{d}=0,79\right)$. 
Posteriormente, análisis elementales de composición, globales y locales, fueron llevados a cabo por medio de un sistema de espectrometría de rayos $X$ en dispersión de energía, asociado con un microscopio electrónico de barrido (MEB/EDXS). El principal interés de esta asociación fue la posibilidad de realizar análisis globales del metal/aleación, aún presente, apartando los productos de corrosión, así como análisis locales, focalizando el haz sobre una inclusión o un grano (Pernot, 2002).

\section{RESULTADOS}

\section{1. Dispositivos de calentamiento: hornos}

Teóricamente, los tipos de hornos encontrados en talleres metalúrgicos de transformación se dividen en dos grandes familias, dependiendo de su función: horno de fusión y horno de recalentamiento. Estos aparatos metalúrgicos, muchas veces mal conservados o frecuentemente confundidos con fogones de combustión simples, son raras veces descubiertos o reconocidos in situ.

Cuatro dispositivos se reparten en el taller 27-30 (fig. 3a). En la zona sureste del ambiente, los arqueólogos registraron en el suelo una amplia zona de combustión o fogón, cuya forma y dimensiones (¿hoyo, hondonada?) no son especificadas (Chiguala et al., 2003). Estaba asociada a varios fragmentos de cerámica de pasta gruesa con restos de metal en vitrificaciones, pequeñas escorias de fusión, gotitas y salpicaduras de cobre, probablemente caídas del crisol durante el proceso de la colada del metal6, así como pequeñas toberas.

Cerca a esta zona carbonosa, se encontró un yunque fragmentado de piedra in situ (fig. 3b). Mide $29 \mathrm{~cm}$ por $24 \mathrm{~cm}$ con un espesor de $6 \mathrm{~cm}$ y pesa aproximadamente $9 \mathrm{~kg}$. La superficie rugosa de este yunque presentaba algunos restos de bolas metálicas adheridas; las gotitas y salpicaduras de metal se registraron dispersas alrededor suyo. Las dimensiones y las características de esta estructura no parecen específicamente asociadas a operaciones de deformación como el martillado, sino más bien a procesos diversos como el machacado u otras operaciones que entran necesariamente en la cadena operativa de un taller metalúrgico: preparación de las pastas arcillosas adecuadas para fabricar los crisoles, las toberas y/o de los moldes, operaciones de desmolder, etc.

Los fragmentos de cerámicas de pasta gruesa con restos de metal en vitrificaciones (fig. 4) podrían corresponder por ejemplo a los restos de una capa de arcilla gruesa enlucida en un hoyo acondicionado en el suelo, muy similar a los tipos de hornos que registró el equipo de Shimada en el taller de fundición de Pampa Grande (1994: 206). Este conjunto de indicios materiales suele indicar cuáles actividades de fusión (preparación de metal o de aleaciones) eran realizadas in situ. Sin embargo, queda

6 Estos desechos son generalmente reciclados, pero a veces da la casualidad que se encuentran alguno de ellos.

7 Acción que consiste en romper el molde para retirar la(s) pieza(s) vaciada(s). 
Huacas de Moche: estudio arqueométrico de un taller de transformación de cobre

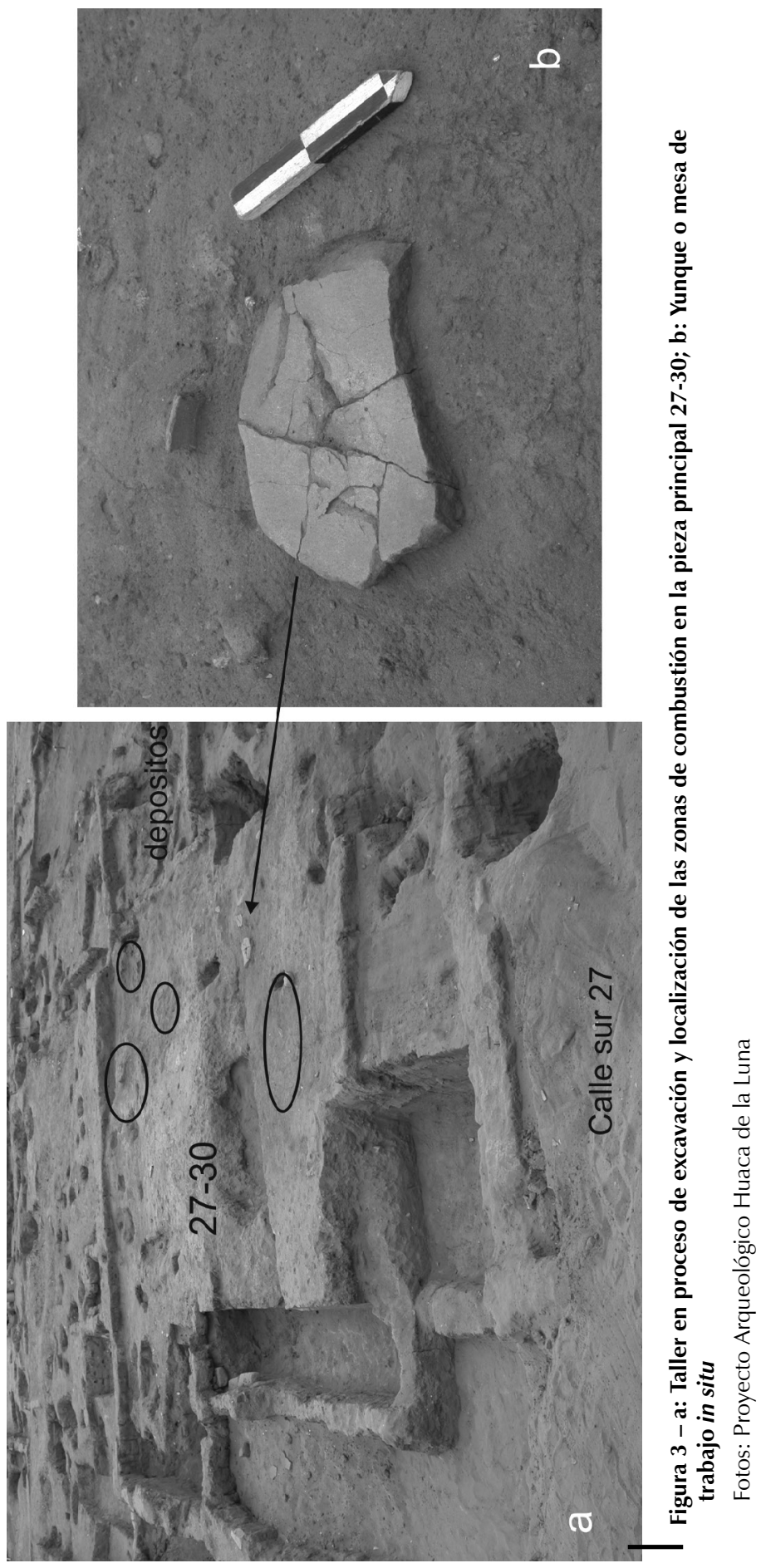




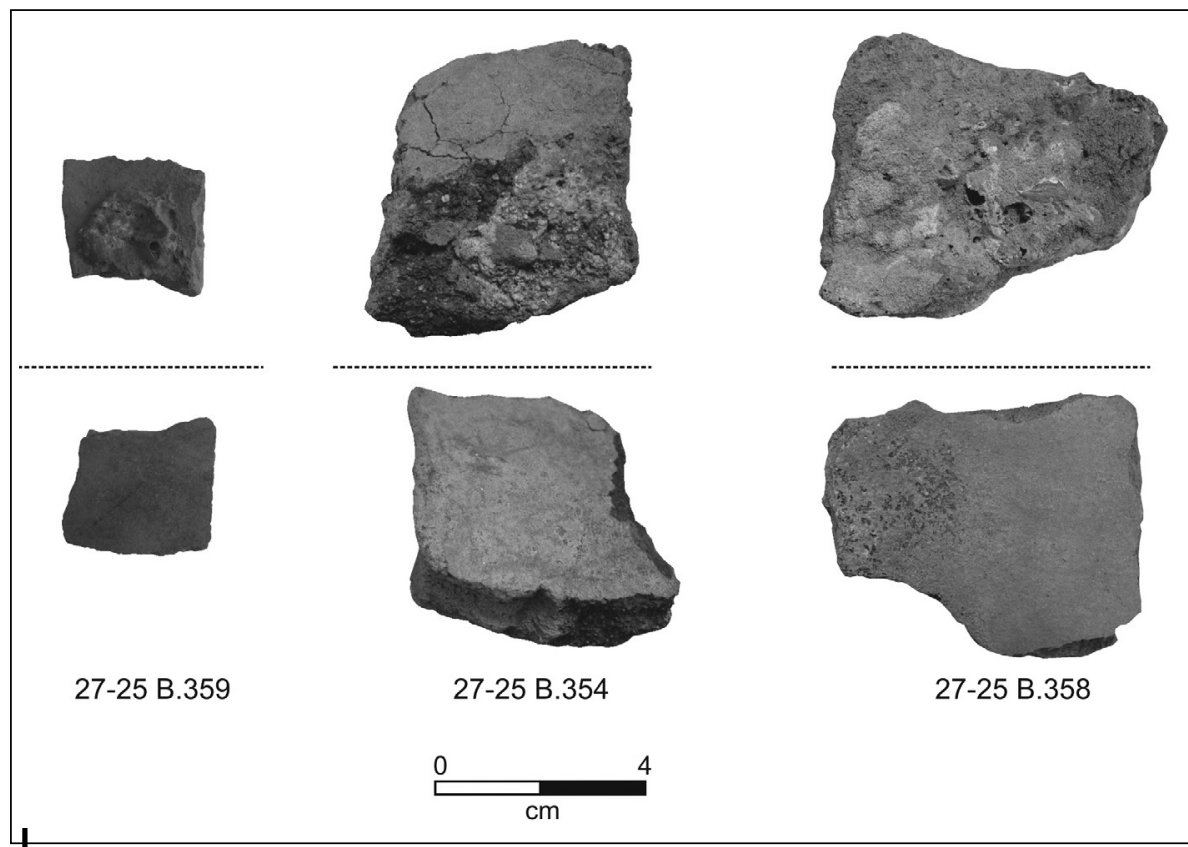

Figura 4 - Fragmentos de cerámicas con evidencias de vitrificaciones de aspecto «burbujoso» que resultan de actividades de fundición del cobre $\left(1083^{\circ} \mathrm{C}\right)$

difícil determinar con certeza el tipo exacto de operación llevado a cabo en esta parte del taller.

Del norte al sureste del espacio 27-30, tres zonas circulares de combustión están también señaladas (Chiguala et al., 2003; Rengifo \& Rojas, 2004). La primera se localiza contra la pared del límite norte del ambiente, las dos otras se ubican, un poco hacia atrás, en el centro del ambiente. Estas dos últimas, siendo de forma muy simple, a modo de pequeños fogones, parecen corresponder a hornos de recocido8. Entre los tres fogones se destaca una estructura circular simple, de aproximadamente $30 \mathrm{~cm}$ de diámetro, con gran cantidad de carbón y ceniza blanca. En el centro de la estructura era colocado sobre el suelo un adobe fuertemente rubificado por el fuego (fig. 5). Este dispositivo circular abierto correspondía muy probablemente a un horno de fusión. Así, el crisol conteniendo el metal a derretir se acuña sobre el adobe en el centro del fogón; el horno, alimentado con carbón de madera y ventilado con uno o varios sopletes, permite llegar a la fusión

8 Los hornos de recocido entran en el proceso de fabricación de piezas deformadas plásticamente. El trabajo en frío hace que rápidamente el metal se vuelva frágil y quebradizo. Para facilitar la propagación de las dislocaciones y homogeneizar la nueva estructura cristalina del metal, es decir para que el metal trabajado pueda ser nuevamente deformado plásticamente sin miedo a que se quiebre, el artesano aplica un recocido de recristalización a la pieza, lo cual es un recalentamiento lento, debajo del punto de fusión. Recocidos sucesivos están, necesariamente, practicados durante el trabajo del martillado para obtener láminas finas. 


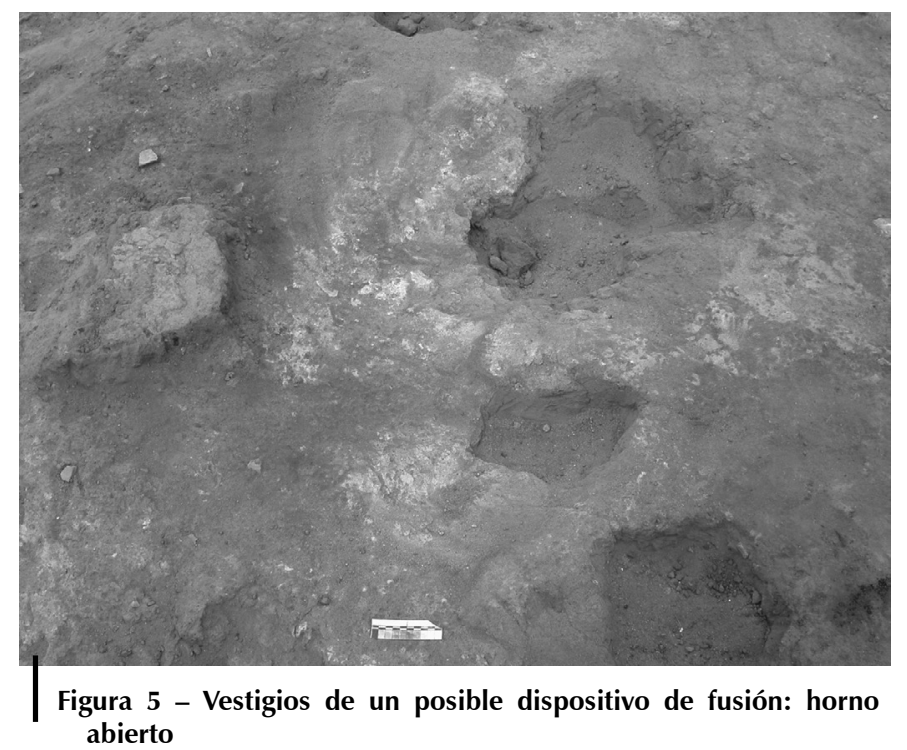

Foto: Proyecto Arqueológico Huaca de la Luna

del cobre $\left(1083^{\circ} \mathrm{C}\right)$ o aleaciones con base de cobre (aproximadamente $950^{\circ} \mathrm{C}$, dependiendo de la aleación). La localización de este horno contra la pared del ambiente, podría explicarse por la búsqueda, de parte de los metalurgistas, de un lugar más oscuro que les permitirá garantizar la buena lectura de las temperaturas del metal (para la colada) y/o para efectuar operaciones de fundición al abrigo de los corrientes de aire; estas implican, en efecto, un control cuidoso de las temperaturas del horno (Chardron-Picault \& Pernot, 1999: 197).

La ventilación controlada de los hornos se efectuaba mediante sopletes, cuya evidencia arqueológica son las 27 toberas de arcilla cruda registradas (fig. 6). Estas pequeñas toberas, de aproximadamente $3 \mathrm{~cm}$ de largo, son de forma recta y presentan pocas alteraciones al nivel de su nariz o extremo inferior: vitrificaciones, restos de metal adherido, fisuras, etc. Solo algunos especímenes muestran ligeras alteraciones al nivel del extremo inferior como zonas de color negro y, a veces, pequeñas zonas microporosas ligeramente vitrificadas. Estas observaciones sugerían que la nariz de ciertas toberas estuvo directamente en contacto con la zona de combustión, en atmósfera reductora (lo que explica el color negro); el cuerpo de la tobera (rojizo), quedó expuesto al aire, en atmósfera oxidante. Sin embargo, la gran mayoría del corpus de las toberas presentaba un color rojizo homogéneo o ligeramente anaranjado en la parte de la nariz. Estas observaciones indican que estas no estuvieron en contacto con el fogón. Las pequeñas dimensiones de las toberas, así como las características de los tipos de alteración observados parecen más bien indicar que se ubicaban encima del crisol, inclinados a $45^{\circ}$, de manera que el chorro de aire esté directamente dirigido sobre el metal dispuesto en el crisol (Oberweiler, 2005). 


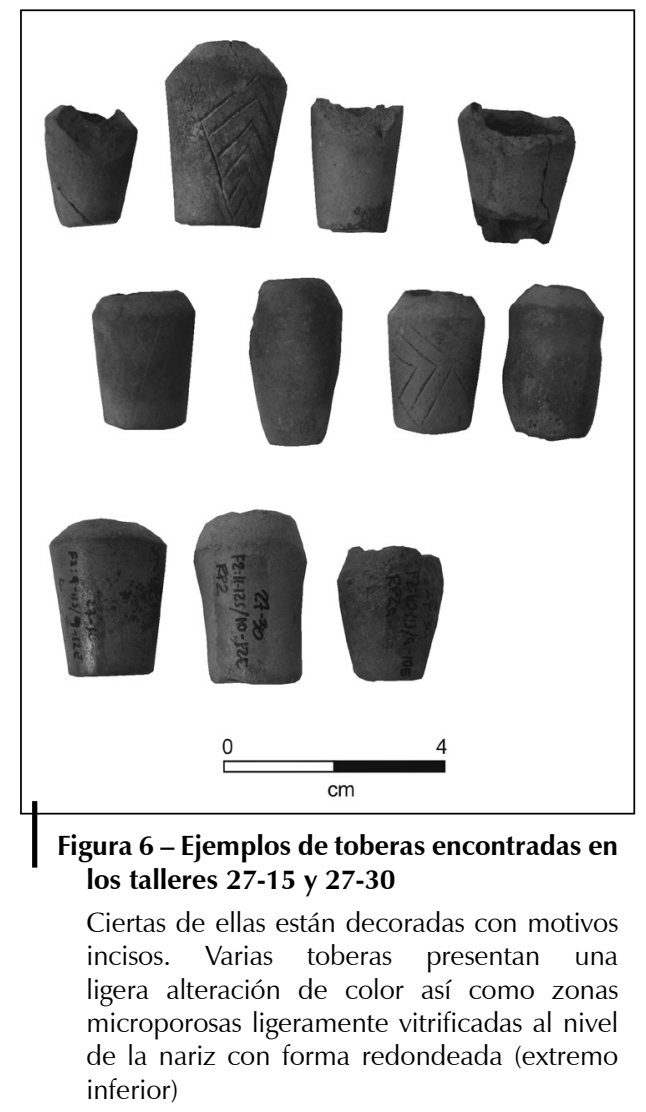

\section{2. Recipientes de «cerámica»: los crisoles}

Los fragmentos de crisoles y de moldes son vestigios materiales directos de las actividades metalúrgicas de fusión. Más de 90 fragmentos claramente identificados como crisoles fueron descubiertos en los espacios 27-30, 27-15, 27-25 et 27-27 (fig. 7). Se caracterizan por una pasta arcillosa muy porosa, de color gris oscuro con, en algunos casos, restos de pequeñas inclusiones claras. Generalmente, el lado convexo de los crisoles o de fragmentos de crisoles es colorado por zonas de color verde y roja, y las vitrificaciones son muchas veces distinguibles. Ninguno de los fragmentos de crisoles, registrados en el taller del CA27 presentaba vitrificaciones visibles al ojo; la superficie interna solo presentaba una fina capa de óxidos de cobre que podría indicar que los crisoles habían servido para una sola operación de fundición. La superficie alisada del lado cóncavo de los fragmentos observados indica que la preparación de estos recipientes ha sido relativamente cuidada. La superficie, de color gris a dominante rosada, no presentaba restos de óxidos de cobre. El lado cóncavo corresponde a la parte que estará directamente en contacto con el horno. Su color rosado resulta de la atmósfera oxidante en 
la cual se expone el crisol al retirarse del horno para realizar la colada del metal derretido (Chardron-Picault \& Pernot, 1999: 188).

La forma y dimensiones de crisoles enteros utilizados por los metalurgistas mochicas eran, antes del presente estudio, totalmente desconocidas. Sin embargo, la observación del fragmento 27-30 B.351 nos ayudó para reconstituir la forma aproximada de ciertos tipos de crisoles utilizados en este taller (fig. 8). El crisol tiene forma de pequeña copela, de $5 \mathrm{~cm}$ de diámetro y $3 \mathrm{~cm}$ de profundidad, a la cual, por lo menos, un asa ha sido modelada en el borde; su volumen es aproximadamente $30 \mathrm{ml}$, o sea 0,03 litros de metal.

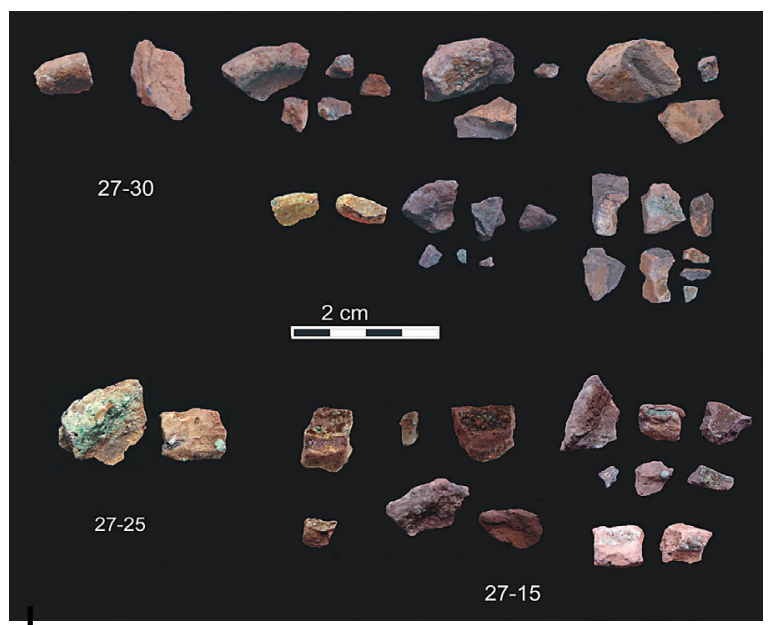

Figura 7 - Ejemplos de fragmentos de crisoles registrados en el contexto primario y el relleno asociado al piso (penultima) de los espacios 27-15, 27-30 y el depósito 27-25

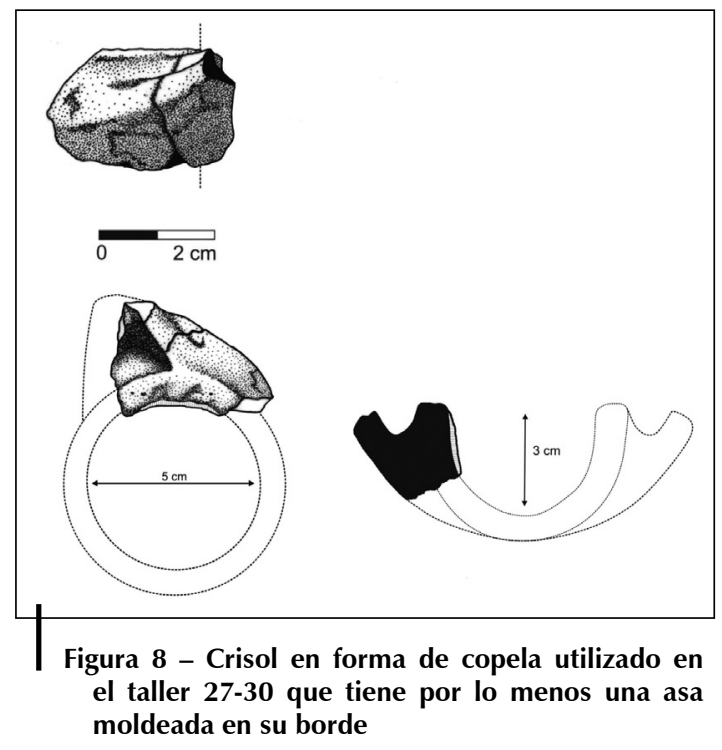

Dibujo realizado a partir del fragmento 27-30 B.351. El volumen total del recipiente es $30 \mathrm{ml}$. El volumen calculado es aproximativo porque este tipo de recipiente nunca se rellena totalmente (Dibujo: $A$. Rohfritsch)

\section{2. 1. ¿Que derretían los metalurgistas de la huaca de la Luna en estos crisoles?}

Dos fragmentos de crisoles fueron sometidos a análisis de laboratorio con el fin de determinar, primero, cuál(es) tipo(s) de metal(es) y/o aleación(es) era(n) fundido(s) en estos recipientes; y luego, para tratar de obtener informaciones relativas a la(s) receta(s) de preparación de los crisoles (fig. 9). Los primeros resultados presentados en este trabajo constituyen un estado inicial y exploratorio de investigación puesto que ningún otro estudio comparativo existe; estudios complementarios deben ser desarrollados en este campo. 


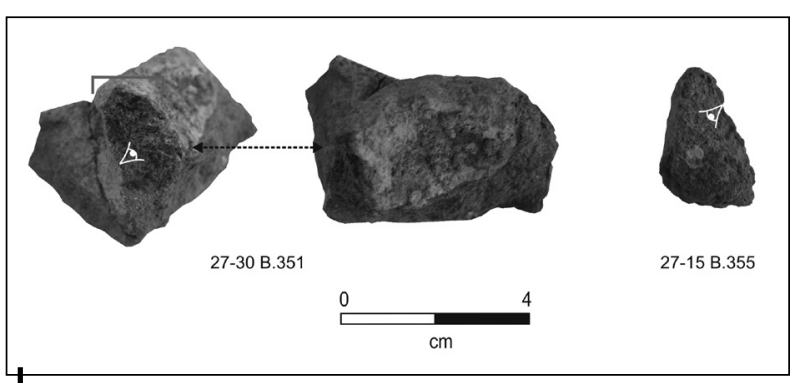

Figura 9 - Localización de la muestra efectuada en sección transversal en el fragmento de crisol 27-30 B.351

El segundo fragmento 27-15 B.355 ha sido totalmente engastado en resina y observado en sección transversal

resultados del estudio del 27-30 B.351.
Se realizaron dos secciones de fragmentos de crisoles, engastadas y luego pulidas. Se siguió el mismo protocolo, previamente descrito, para realizar exámenes microscópicos y análisis MEB/EDXS.

El espesor del cuerpo de los crisoles está comprendido entre 12 y $20 \mathrm{~mm}$. La observación en sección transversal del fragmento 27-30 B.351 muestra tres zonas distintas de aspecto muy heterogéneo (fig. 10). La segunda muestra considerada, 27-15 B.355, presenta las mismas características analíticas; solo presentaremos los

La zona 1 corresponde a la pasta original del crisol (fig. 10). Esta amplia zona de 8 a $15 \mathrm{~mm}$ de espesor es muy porosa. Los poros observados se relacionan probablemente con improntas del desgrasante orgánico (excrementos de animales, pelos, fibras vegetales, etc.) utilizado en la preparación de la pasta del crisol (Valencia Espinoza, 2001: 38; Oberweiler, 2005; Fraresso, 2008); sin

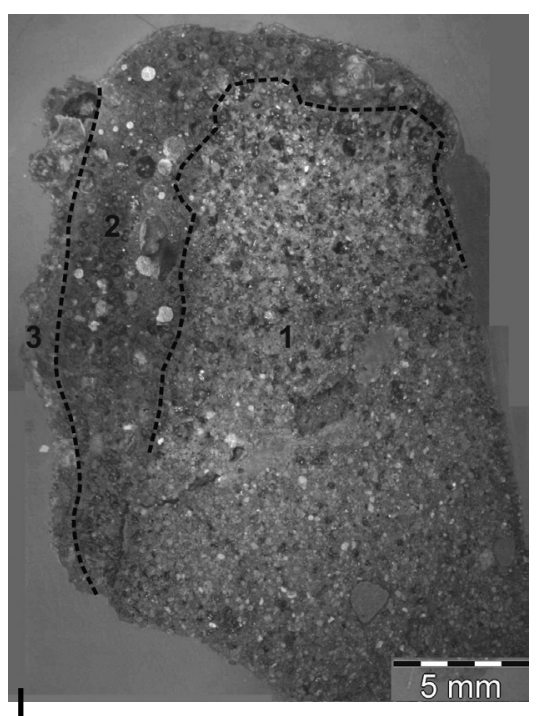

Figura 10 - Sección pulida del corte transversal del fragmento de crisol 2730 B.351 observado con microscopia óptica

Una neta estratificación de zonas heterogéneas es visible: (1), (2) y (3) embargo, es difícil, en este caso, identificar precisamente la naturaleza exacta del desgrasante (vegetal o animal). La presencia de granos de cuarzos es dominante; estos son visibles al ojo y algunos tienen un tamaño del orden del milímetro. Los análisis llevados a cabo en esta matriz de color gris oscuro, y presentados en la figura 11, indican naturalmente la presencia mayoritaria del silicio (65-70 \% en $\mathrm{SiO}_{2}$ ), siendo los otros elementos mayores constituyentes de la pasta arcillosa: el aluminio (15-17\% en $\left.\mathrm{Al}_{2} \mathrm{O}_{3}\right)$ y el hierro $\left(7,5-8,5 \%\right.$ en $\mathrm{Fe}_{2} \mathrm{O}_{3}$ ). El color gris oscuro de la pasta interna resulta del ámbito reductor generado por el horno alimentado en carbón de madera y el metal durante la fusión (Chardron-Picault \& Pernot, 1999: 188).

La zona 2 es más heterogénea y muestra zonas de diferentes colores (fig. 10). Esta capa con color dominante rojo, tiene un espesor entre 3 y 4 milímetros. Está salpicada por zonas de color verde intenso que se explican por la presencia del cobre y se distinguen específicamente en esta capa nódulos metálicos de dimensiones variables (de $100 \mu \mathrm{m}$ a $1 \mathrm{~mm}$ ). Los análisis globales en la zona roja muestran una disminución sensible de los porcentajes en silicio (46-52 \% en $\mathrm{SiO}_{2}$ ), 
en aluminio $\left(8,5-15 \%\right.$ en $\mathrm{Al}_{2} \mathrm{O}_{3}$ ) y hierro (3-4 \% en $\mathrm{Fe}_{2} \mathrm{O}_{3}$ ) en paralelo a la aparición de óxidos de cobre, entre 5 y $12 \%$ en $\mathrm{CuO}$ (lo que explica el color) y un fuerte aumento del calcio (17-23\% en CaO). Subrayamos también la aparición del fósforo (2-3 \% en $\mathrm{P}_{2} \mathrm{O}_{5}$ ) que está asociado al calcio (fig. 11). La presencia de fosfato de calcio parece indicar el añadido intencional de ceniza de huesos (probablemente animales) en la preparación de la pasta arcillosa como desgrasante, pero otros estudios comparativos son necesarios para averiguar la receta de preparación de estos crisoles9. Se observan igualmente, en esta capa, algunos poros que resultan del encierro de gases durante la vitrificación de «escorias internas» en los crisoles de fusión (Queixalos et al., 1987). Numerosos nódulos metálicos se observan también en este estrato que atestiguan tanto la presencia de escorias internas, como de la fusión del metal en el recipiente.

\begin{tabular}{|c|c|c|c|c|c|c|c|c|c|c|}
\hline & $\mathrm{Na}_{2} \mathrm{O}$ & $\mathrm{MgO}$ & $\mathrm{Al}_{2} \mathrm{O}_{3}$ & $\mathrm{SiO}_{2}$ & $\mathrm{P}_{2} \mathrm{O}_{5}$ & $\mathrm{~K}_{2} \mathrm{O}$ & $\mathrm{CaO}$ & $\mathrm{TiO}_{2}$ & $\mathrm{Fe}_{2} \mathrm{O}_{3}$ & $\mathrm{CuO}$ \\
\hline $\begin{array}{c}\text { Zona } 1 \\
\text { gris }\end{array}$ & $1,5-2$ & $\begin{array}{l}1- \\
1,5\end{array}$ & $\begin{array}{c}15- \\
17\end{array}$ & $\begin{array}{c}65- \\
70\end{array}$ & $\mathrm{Nd}$ & $2-3$ & $1-2$ & 0,7 & $\begin{array}{c}7,5- \\
8,5\end{array}$ & $\mathrm{Nd}$ \\
\hline $\begin{array}{c}\text { Zona } 2 \\
\text { rojo }\end{array}$ & $\begin{array}{c}1,5- \\
2,5\end{array}$ & $\begin{array}{l}2- \\
3,5\end{array}$ & $\begin{array}{c}8,5- \\
15\end{array}$ & $\begin{array}{c}46- \\
52\end{array}$ & $\begin{array}{l}1,5 \\
-3\end{array}$ & $1-2$ & $\begin{array}{c}17- \\
23\end{array}$ & 0,5 & $3-4$ & $5-12$ \\
\hline $\begin{array}{c}\text { Zona } 3 \\
\text { verde }\end{array}$ & $\mathrm{Nd}$ & $1-2$ & $5-7$ & $\begin{array}{c}42- \\
60\end{array}$ & 1 & $\begin{array}{l}1- \\
1,5\end{array}$ & $2-3$ & $\mathrm{Nd}$ & $\begin{array}{r}1,5 \\
-2,5\end{array}$ & $30-42$ \\
\hline
\end{tabular}

Figura 11 - Composición elemental de óxidos (wt\%) de cada estrato observado en la sección transversal del fragmento de crisol 27-30 B.351

Teniendo en cuenta la gran heterogeneidad del material, se presentaron los porcentajes mínimos y máximos de los diferentes elementos constitutivos. Los nódulos metálicos no han sido tomados en cuenta en esta serie de análisis. $\mathrm{Nd}=$ no detectado

Una segunda serie de análisis puntuales se llevó a cabo con el fin de determinar qué tipo de metal o aleación se fundía(n) en estos crisoles. Se reportaron los resultados en la figura 12.

Los nódulos metálicos están esencialmente compuestos de cobre aleado con oro, en porcentajes variables (entre 2 y $11 \%$ ). Los bajos porcentajes de plata detectados ( $\leq$ a $2 \%$ ) corresponden seguramente a impurezas naturales del oro.

A este paso del estudio, dos hipótesis pueden ser consideradas:

1) aleaciones ya «listas» bajo forma de pequeños lingotes y traídos al taller desde otro lugar, los cuales eran refundidos en los crisoles del taller para refinarlos;

2) o el mismo metalurgista preparaba aleaciones en este espacio, en cantidades previamente definidas, dependiendo de los objetivos técnicos y/o estéticos buscados.

9 Una mezcla de arcilla con ceniza de huesos parece haber sido aplicada sobre la superficie interna del crisol. Este tipo de enlucido (o cemento) facilitará la separación de las impurezas presentes en el metal o la aleación a fundir; es decir que una parte de las suciedades serán «chupadas» por el cemento. 


\begin{tabular}{|c|c|c|c|c|c|c|}
\hline Metal o & Código & Tipo de objeto & \multicolumn{3}{|c|}{ Composición (wt\%) } & \multirow[t]{2}{*}{ Nota } \\
\hline & & & $\begin{array}{l}\mathrm{Cu} \\
(\%)\end{array}$ & $\mathrm{Au}(\%)$ & $\begin{array}{l}\mathrm{Ag} \\
(\%)\end{array}$ & \\
\hline \multirow{10}{*}{ Cobre } & 27-15 B.109 & $\begin{array}{c}\text { Escoria } \\
\text { Composición de } \\
\text { nódulos metálicos } \\
\text { presentes en la matriz } \\
\text { vítrea } \\
\end{array}$ & $97-99$ & nd & nd & \\
\hline & $27-15$ B.105 & Fragmento de barra & 99,8 & nd & nd & $\mathrm{S}(0,2 \%)$ \\
\hline & 27-15 B.109 & Gota de metal & 100 & nd & nd & \\
\hline & $27-15$ B.102 & Lingote & 100 & nd & nd & \\
\hline & $27-30$ B. 17 & Gota de metal & 99,7 & nd & nd & Si $(0,3 \%)$ \\
\hline & $27-30$ B. 10 & Gota de metal & 100 & nd & nd & \\
\hline & $27-30$ B.17 & Cinta doblada & 100 & nd & nd & \\
\hline & 27-30 B.68 & $\begin{array}{c}\text { Masa circular } \\
\text { deformada }\end{array}$ & 100 & nd & nd & \\
\hline & 27-30 B.09 & $\begin{array}{l}\text { Barra con sección } \\
\text { rectangular }\end{array}$ & 100 & nd & nd & \\
\hline & 27-25 B.25 & Espátula & 100 & nd & nd & $\begin{array}{c}\text { Tratamiento } \\
\text { electroquimico } \\
\end{array}$ \\
\hline \multirow{2}{*}{$\begin{array}{l}\text { Aleaciones } \\
\text { (Cu-Au-Ag) } \\
\text { (Cu-Au) }\end{array}$} & 27-30 B.62 & $\begin{array}{c}\text { Varilla } \\
\text { Fallo de fabricación }\end{array}$ & 76 & 19,5 & 4,5 & \\
\hline & 27-15 B.59 & $\begin{array}{c}\text { Varilla } \\
\text { abandonada en proceso }\end{array}$ & 98 & 1,5 & 0,5 & \\
\hline
\end{tabular}

Figura 12 - Composiciones elementales de los nódulos metálicos observados en los cortes transversales de los fragmentos de crisoles 27-30 B.351 y 27-15 B.355. Los resultados están normalizados al $100 \%$ (wt\%). Los porcentajes del oro son muy variables, entre 2 y $11 \%$. $\mathrm{Nd}=$ no detectado

La segunda hipótesis parece la más probable. La gran heterogeneidad de los valores del oro, así como la presencia de dos nódulos en cobre no aleado, identificados en la zona 2 del crisol 27-15 B.355, prueban claramente que estos crisoles servían para preparar aleaciones con base de cobre y que el proceso de la fusión (la mezcla) no era terminado. Es, entonces, a partir de cobre no aleado, probablemente bajo forma de pequeños lingotes, que el metalurgista preparaba sus aleaciones, añadiendo pocas cantidades de oro o practicando el reciclado de desechos o piezas fuera de uso como caídas de metales (recortes de láminas de cobre dorado por ejemplo) o piezas por reciclar conteniendo poco porcentaje de oro.

La zona 3, la cual pertenece a la superficie interna del borde del crisol, tiene un espesor de $1 \mathrm{~mm}$. Presenta un color verde y gris, esencialmente relacionada a la presencia de óxidos de cobre, entre 30 y $42 \%$ en $\mathrm{CuO}$ (fig. 11). Esta fina capa corresponde a la pared interna del crisol (fig. 10).

La dimensión y la forma de los crisoles (de 0,03 I de capacidad), así como aquellas de las toberas, demuestran que pequeñas cantidades de metal (300 g de cobre máximo), y consecuentemente, objetos de muy pequeñas dimensiones, eran fabricados en el taller de la huaca de la Luna. Los dos fragmentos de crisoles estudiados en este trabajo están constituidos por una mezcla compuesta por una arcilla, un desgrasante orgánico y un desgrasante mineral. Señalamos que esta 
pasta arcillosa responde apropiadamente a las propiedades mecánicas necesarias para la fundición del cobre y de aleaciones con base de cobre: resistencia a altas temperaturas y a los choques térmicos que pueden producirse durante la fusión del metal en el crisol. Una preparación particularmente cuidadosa ha sido aplicada para la fabricación de estos recipientes pero es difícil determinar, a partir de estos únicos ejemplos, si sus utilizaciones eran destinadas a una sola o varias operaciones de fusión. Las recetas precisas utilizadas por los artesanos del valle de Moche quedan además por explorar. El desgrasante orgánico (animal o vegetal), la naturaleza mineral del desgrasante mineral, el añadido de cenizas de huesos en la mezcla así como las proporciones exactas deben ser estudiadas en futuros trabajos.

\section{3. Los «desechos» metálicos del taller}

El material metálico está constituido por pequeños «desechos», es decir pedazos de metal que pesan algunos gramos; ningún objeto precioso (de oro o plata) ha sido registrado en los espacios 27-30 ó 27-15 del taller. Los desechos suelen identificarse como bases de cobre, cuyas composiciones químicas quedan por determinar. El corpus registrado comprende caídas de metales (recortes de láminas), esbozos abandonados durante el proceso de fabricación o fallas de fabricación (barras y varillas de sección rectangular o circular, semi cuenta), subproductos resultantes de operaciones de fundición (escorias de fusión10, gotitas y salpicaduras), un pequeño lingote y semi productos (barras, masas metálicas circulares) y por fin piezas acabadas que pueden ser productos manufacturados en el mismo sitio o piezas fuera de uso depositadas en el taller y destinadas a un futuro reciclado. Trataremos los objetos acabados con mucha prudencia puesto que ningún criterio permite determinar si estuvieron fabricados o importados en el taller: recordamos que no conocemos el tipo de organización relacionado a las prácticas del reciclado en las actividades metalúrgicas mochicas, y más globalmente a aquellas del antiguo Perú.

\section{3. 1. Objetos seleccionados}

Una selección de 15 piezas metálicas, de las cuales se efectuó tomas de muestras mínimas, se hizo para realizar la lectura tecnológica de los materiales y procesos involucrados en el taller mediante las herramientas de laboratorio. En la totalidad del corpus observado, ninguna pieza presentaba huellas de herramientas visibles al ojo. Entre los objetos seleccionados, se pueden distinguir cinco categorías de objetos: desechos resultantes de operaciones de derretido o fusión (dos escorias y tres gotitas), piezas en curso de fabricación (una media cuenta, dos fragmentos de barras con espesores respectivas de 2 y $5 \mathrm{~mm}$ y una masa metálica circular deformada), fallos de fabricación y caídas de trabajo (una barra con sección

10 Impurezas que suben a la superficie de metal en fusión. El artesano puede sacar estos residuos con un palillo o una varilla. 
rectangular, una cinta doblada tres veces y un fragmento de lámina con evidencias de restos de dorado), semi productos (una masa metálica y una barra con sección rectangular de $2 \mathrm{~mm}$ de grosor) y, finalmente, un objeto acabado (una espátula). El conjunto de las muestras presenta un buen estado de conservación. De la muestra total estudiada e ilustrada en la figura 13, solamente tres muestras (fragmento de lámina dorada, media perla y una gotita) estaban fuertemente corroídas, es decir que no quedaba metal susceptible de ser analizado.

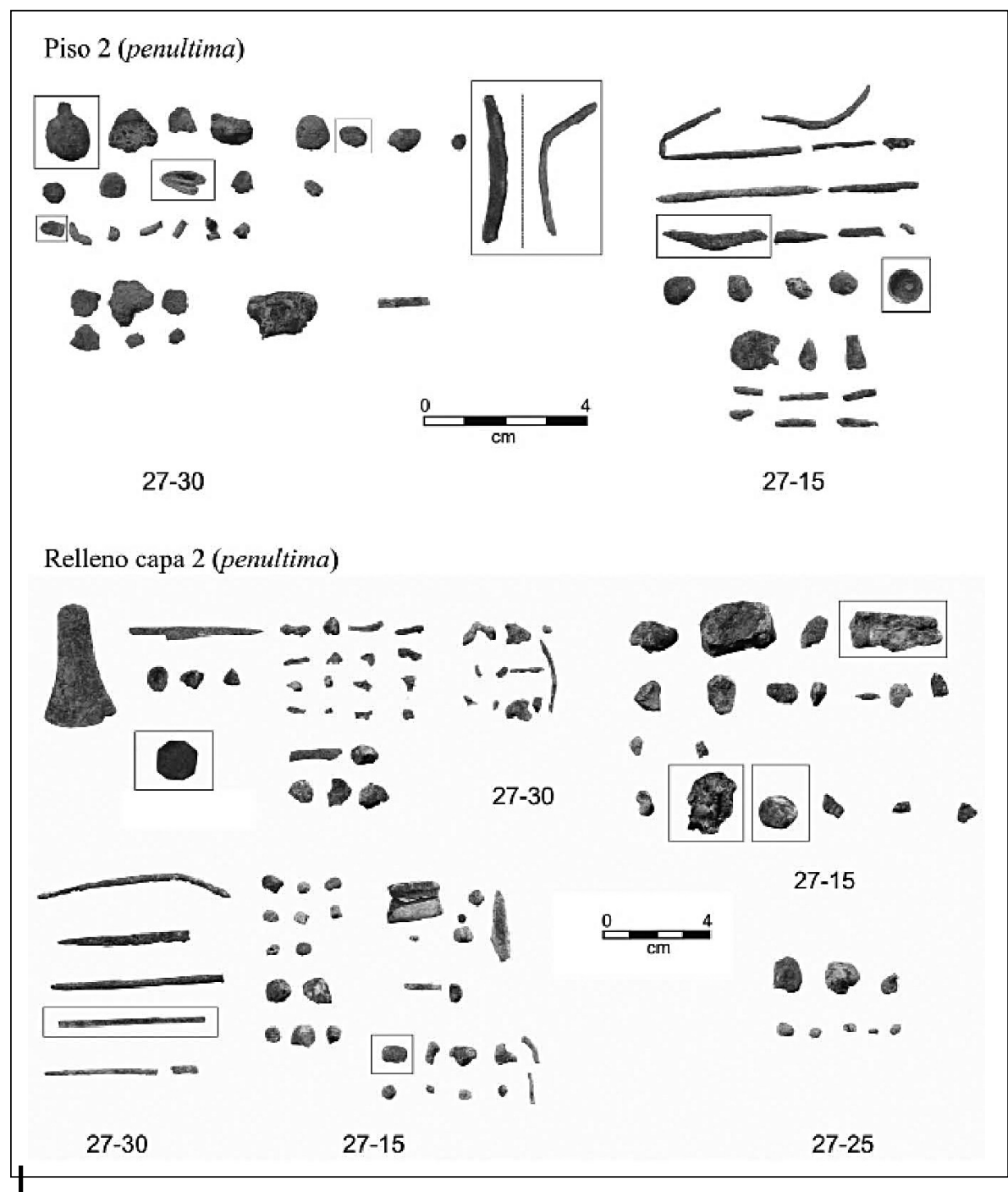

Figura 13 - Selección efectuada a partir del corpus de piezas metálicas registradas en los espacios 27-15 y 27-30 (enmarcados)

El espacio 27-25 corresponde a un pequeño depósito 
Huacas de Moche: estudio arqueométrico de un taller de transformación de cobre

\section{3. 2. Composición de los metales y aleaciones}

Los resultados de las composiciones elementales obtenidas por cada pieza han sido reportadas en la figure 14. El corpus estudiado se divide en tres grandes clases de metales y aleaciones:

- Cobre no aleado (10 casos).

- Cobre poco aleado, con 1,5\% de oro, seguramente resultante del reciclado (1 caso).

- Aleación ternaria con aproximadamente 20 \% de oro, tipo Cu-Au-Ag tumbaga (1 caso).

Entre los vestigios de cobre no aleado, se destacan claramente cuatro piezas que corresponden a desechos resultantes de operaciones de fundición, como las escorias de fusión y las gotitas de cobre. Cinco otros corresponden a vestigios de la producción local (27-15 B.105, 27-15 B.102, 27-30 B.17, 27-30 B.68 y 27-30 B.09). Están compuestos de cobre remarcablemente «limpio», excepto el fragmento de barra deformada 27-15 B.105 que presenta un bajo porcentaje de azufre $(0,2 \%)$; el azufre aquí presente en estado de impureza está seguramente relacionado al origen del mineral.

\begin{tabular}{|c|c|c|c|c|c|c|}
\hline Metal o & Código & Tipo de objeto & \multicolumn{3}{|c|}{ Composición (wt\%) } & \multirow[t]{2}{*}{ Nota } \\
\hline & & & $\begin{array}{l}\mathrm{Cu} \\
(\%)\end{array}$ & $\begin{array}{l}\mathrm{Au} \\
(\%)\end{array}$ & $\begin{array}{l}\mathrm{Ag} \\
(\%)\end{array}$ & \\
\hline \multirow{10}{*}{ Cobre } & 27-15 B.109 & $\begin{array}{c}\text { Escoria } \\
\text { Composición de nódulos } \\
\text { metálicos presentes en la } \\
\text { matriz vítrea }\end{array}$ & $97-99$ & nd & nd & \\
\hline & 27-15 B.105 & Fragmento de barra & 99,8 & nd & nd & $\mathrm{S}(0,2 \%)$ \\
\hline & 27-15 B.109 & Gota de metal & 100 & nd & nd & \\
\hline & $27-15$ B. 102 & Lingote & 100 & nd & nd & \\
\hline & $27-30$ B.17 & Gota de metal & 99,7 & nd & nd & Si $(0,3 \%)$ \\
\hline & $27-30$ B. 10 & Gota de metal & 100 & nd & nd & \\
\hline & $27-30$ B.17 & Cinta doblada & 100 & nd & nd & \\
\hline & $27-30$ B.68 & Masa circular deformada & 100 & nd & nd & \\
\hline & 27-30 B.09 & $\begin{array}{l}\text { Barra con sección } \\
\text { rectangular }\end{array}$ & 100 & nd & nd & \\
\hline & $27-25$ B. 25 & Espátula & 100 & nd & nd & $\begin{array}{c}\text { Tratamiento } \\
\text { electroquímico }\end{array}$ \\
\hline \multirow{2}{*}{$\begin{array}{l}\text { Aleaciones } \\
\text { (Cu-Au-Ag) } \\
(\mathrm{Cu}-\mathrm{Au})\end{array}$} & 27-30 B.62 & $\begin{array}{c}\text { Varilla } \\
\text { Fallo de fabricación }\end{array}$ & 76 & 19,5 & 4,5 & \\
\hline & 27-15 B.59 & $\begin{array}{c}\text { Varilla } \\
\text { abandonada en proceso }\end{array}$ & 98 & 1,5 & 0,5 & \\
\hline \multirow{3}{*}{$\begin{array}{l}\text { Sin metal } \\
\text { sano }\end{array}$} & 27-15 B.59 & Media cuenta & - & - & - & Dorado \\
\hline & $27-30$ B.17 & Fragmento de lamina & - & - & - & Dorado \\
\hline & 27-30 B.17 & Gota de metal & - & - & - & \\
\hline
\end{tabular}

Figura 14 - Composiciones elementales (wt\%) de los diferentes objetos metálicos seleccionados Los resultados están normalizados al $100 \%$ (wt\%). Nd = no detectado 
A continuación, la presencia de cobre poco aleado debe ser subrayada. Los resultados de composición elemental del fragmento de una barra abandonada en curso de fabricación indica la presencia del oro $(1,5 \%$ en $\mathrm{Au})$ y de la plata (0,5 \% en Ag) en bajos porcentajes; estos elementos están presentes en estado de impurezas; la plata siendo una impureza natural del oro. Notamos que la voluntad, de parte del metalurgista de preparar aleaciones con tan poca cantidad de oro es una hipótesis que debemos rechazar. En efecto, añadir 1,5\% de oro no tendrá consecuencias sobre las propiedades mecánicas del cobre y este bajo porcentaje de oro tampoco modificará el color de la aleación. Sin embargo, añadir a un metal «nuevo» una aleación ya «hecha» facilita, por su bajo punto de fusión, el arranque del proceso de aleación (Pernot, 1998a: 124). En el caso presente, es muy probable que la poca cantidad de oro detectada no esté relacionada con la intención de preparar una aleación, sino más bien atestigua la práctica del reciclado, es decir de operaciones de refundición de objetos o desechos (caídas de trabajo, fallos de fabricación, objetos, etc.), tal vez de cobre dorado.

En cambio, la barra con sección rectangular 27-30 B.62 compuesta por $76 \%$ de cobre, $19,5 \%$ de oro y $4,5 \%$ de plata es claramente una aleación ternaria intencional donde la presencia de la plata es probablemente también asociada a la del oro. Esta categoría de aleación corresponde a aleaciones preciosas de color amarillo que serán más duras que el cobre no aleado, pero que quedan, a la vez, relativamente deformables. Este tipo de material duro se pule bien y refleja mejor la luz que los materiales blandos, los cuales son más sensibles a las ralladuras (Chardron-Picault \& Pernot, 1999: 182). Esta clase de aleación, también llamada tumbaga, es muy representativa de las prácticas metalúrgicas mochicas puesto que está, en la mayoría de los casos, relacionada con la fabricación de objetos dorados con la técnica de enriquecimiento de superficie en oro o depletion gilding technique (Lechtman, 1973; 1984).

\section{4. Lectura tecnológica}

\section{4. 1. Subproductos de la fusión del cobre}

Entre los desechos registrados durante la excavación del ambiente 27-30 del taller, hemos seleccionado una pequeña escoria y tres gotitas de salpicaduras las cuales, en contextos de talleres de transformación, son testigos directos de las actividades de fundición (fig. 15).

Las escorias son masas informes que presentan pequeñas dimensiones. Están parcialmente o totalmente vitrificadas y presentan un color oscuro con zonas vitrificadas de color verde a rojo. La sección pulida examinada al microscopio óptico revela la presencia de pequeñas bolas metálicas esparcidas en una ganga de aluminio-silicato (53,3\% en $\mathrm{SiO}_{2}$ et $12,7 \%$ en $\mathrm{Al}_{2} \mathrm{O}_{3}$ ), con calcio (5,6 \% en $\mathrm{CaO})$ y un alto porcentaje en óxidos de cobre (20\% en $\mathrm{CuO}$ ). Observamos la presencia de numerosos poros en la totalidad de la superficie, que corresponden a pozos de difusión de los gases. El tamaño de los nódulos metálicos presentes en 
Huacas de Moche: estudio arqueométrico de un taller de transformación de cobre

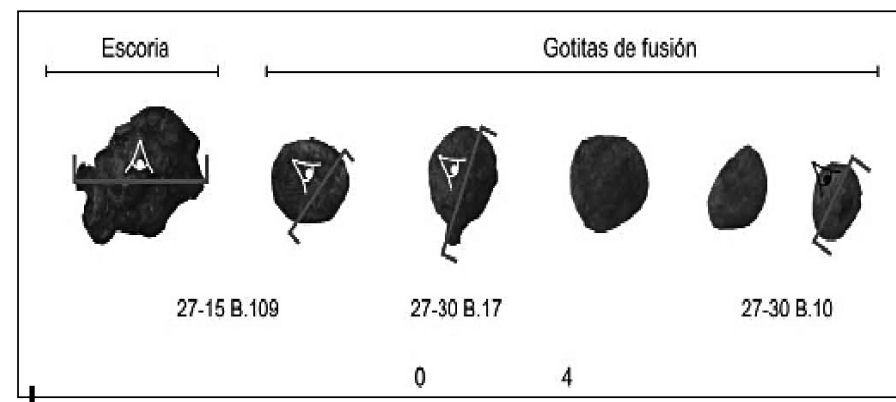

Figura 15 - Pequeña escoria y gotitas de fusión con indicaciones de las zonas de tomas de muestra

la ganga es muy variable, entre 20 y $500 \mu \mathrm{m}$ (fig. 16a). Los nódulos son de cobre no aleado (97-99 \% en $\mathrm{Cu}$ ) lo cual, durante el proceso de fusión del metal en el crisol, puede formar una aleación de tipo eutéctico «Cu-O»que se caracteriza por la formación de dendritas de $\mathrm{Cu}_{2} \mathrm{O}$ (Scott, 1991; Lechtman, 1997) (fig. 16b).
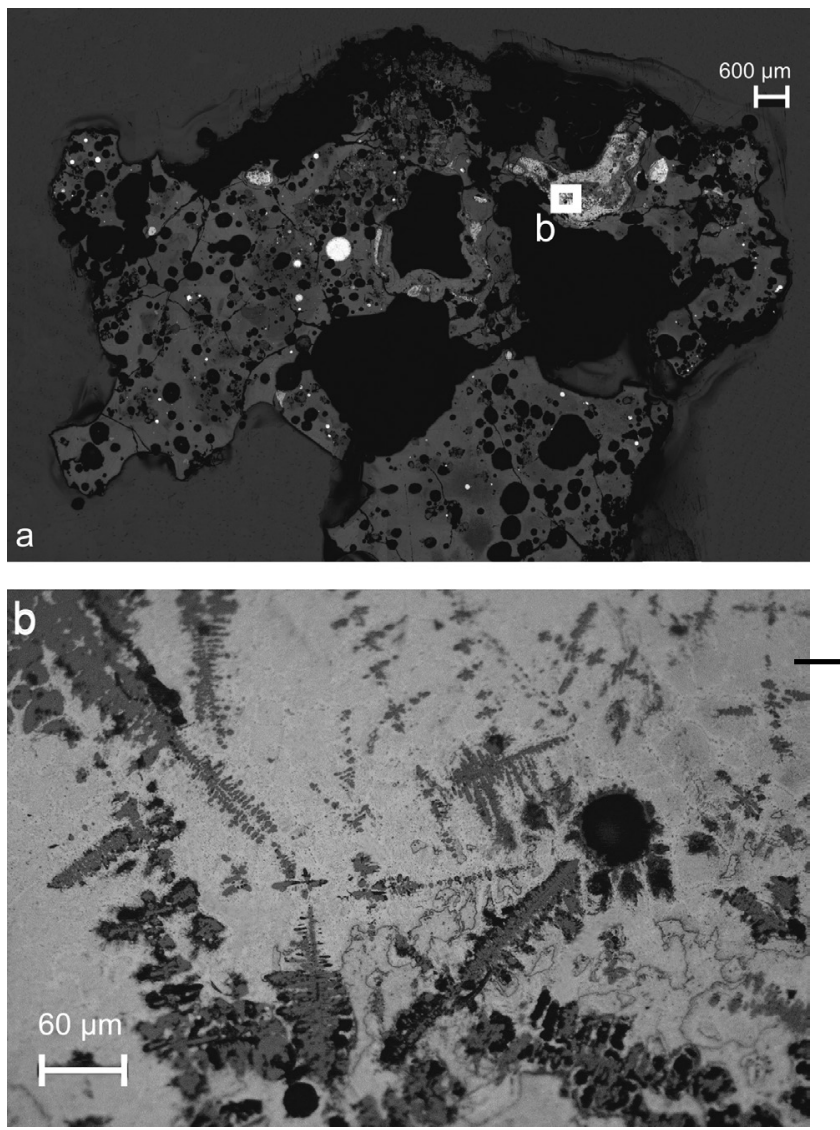

Figura 16 - a: Observación metalográfica en sección pulida de la escoria de fusión (ampliación x10)

Se observan varios poros (en negro) correspondientes a pozos de desgasificación que se forman durante la fusión del metal. Varias inclusiones metálicas (esferas en blanco) se observan en la ganga de la escoria

b: Detalle de una inclusión metálica de cobre (en blanco) donde se observan dendritas de $\mathrm{Cu}_{2} \mathrm{O}$ (en gris oscuro), (ampliación x50) 
Las gotitas y salpicaduras de cobre descubiertas en el taller tienen una forma más o menos esférica, relativamente homogénea, y sus diámetros varían entre 7 y 12 milímetros. La observación de las secciones pulidas de las gotitas 27-15 B.109 y 27-30 B.17 enseñan una matriz de cobre (en amarillo) con poros (en negro) así como el avance de los productos de corrosión del cobre en periferia. Numerosos precipitados de óxidos de cobre $\left(\mathrm{Cu}_{2} \mathrm{O}\right)$, con forma globular, están dispersados en la matriz del cobre (fig. 17). La presencia de

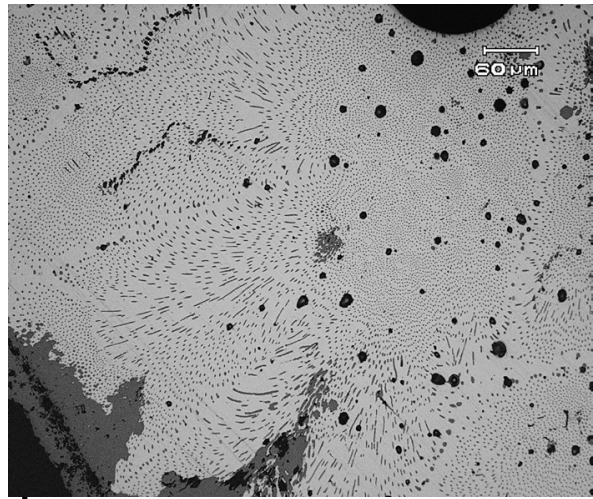

Figura 17 - Observación metalográfica en sección pulida del corte transversal de una gotita de cobre (ampliación x50)

Numerosos nódulos de óxidos están dispersados en la matriz de cobre precipitados se relaciona con las condiciones más o menos oxidantes llevadas durante la fusión del metal en el crisol.

\section{4. 2. Fusión del cobre y preparación de aleaciones}

El trabajo del artesano empieza con la preparación del metal por la fusión de las materias primas que fueron previamente obtenidas en un centro de elaboración; es decir que vuelve a derretir los metales, almacenados bajo forma de lingotes en el taller, para refinarlos y/o preparar aleaciones. Es importante recordar que aún no conocemos la geometría ni las dimensiones de los lingotes o semi productos 11 elegidos por los metalurgistas mochicas. Tampoco sabemos si estuvieron preparados cerca del lugar de extracción y luego transportados al taller de transformación, o bien si estuvieron directamente preparados en este último sitio.

En esta etapa de la cadena operativa, se presentan diferentes posibilidades al artesano. Puede elegir usar un cobre no aleado o también mezclar diferentes metales para preparar aleaciones, operación a la cual el reciclado es muchas veces asociado. Dependiendo de los objetivos técnicos o estéticos buscados, su metal o aleación será, más o menos, purificado a través de operaciones de refinado12. La calidad de los metales y/o aleaciones que definimos, en las culturas antiguas, en término de «limpieza», es un criterio tecnológico importante puesto que refiere al éxito de las operaciones de deformación, es decir que un esbozo sano con pocas inclusiones disminuye los riesgos de la cebadura de fisuras (Pernot, 1994: 851).

11 Un lingote es una pieza de metal o aleación bruta de fundición destinada al transporte y/o al almacenamiento; su geometría no está relacionada con el tipo de pieza que fabricara el orfebre; antes de ser utilizado será refundido. Los semi productos son piezas con geometría precisa: barras, varillas, hilos metálicos, placas etc. (Pernot, 1998a: 123).

12 El refinado, también llamado purificación, es la o las refundición(es) de los metales o aleaciones, que permite separar las inclusiones (el azufre y el plomo en el caso del cobre) o las suciedades presentes en estos últimos. Durante la fusión en el crisol, las inclusiones forman escorias de fusión (capa mugrienta) en la superficie del metal líquido, que el metalurgista quita y bota al costado al mismo tiempo con una varilla de madera dura por ejemplo. 
Entre nuestro muestreo, un pequeño lingote con forma ovalada B27-15 B102 fue identificado (fig. 18a). Está compuesto por cobre no aleado remarcablemente «limpio» (100 \% en Cu). La totalidad de la superficie observada en sección pulida muestra un estado metalúrgico bruto de fundición caracterizado por la presencia de amplios granos dendríticos delimitados por precipitados de óxidos de cobre; los cuales indican que el metal en fusión ha estado en contacto con el aire (fig. 18b). La solidificación del metal se efectuó lentamente en temperatura ambiente.

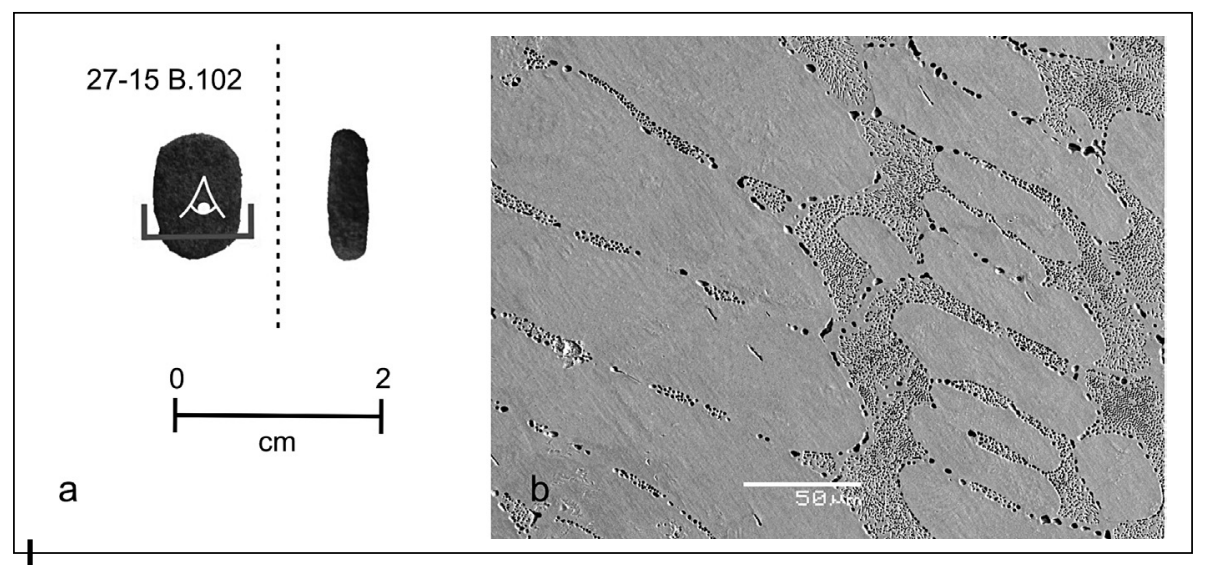

Figura 18 - a: Pequeño lingote de cobre con forma ovala 27-15 B.102. Localización de la zona de toma de muestra

b: Observación en sección transversal de la sección pulida al microscopio electrónico de barrido, en modo electrones retrodispersados (ampliación x450)

Estado metalúrgico bruto de fundición. Los granos dendríticos de cobre (gris claro) están delimitados por precipitados de óxidos de cobre $\left(\mathrm{Cu}_{2} \mathrm{O}\right)$, en gris oscuro

\section{4. 3. Esbozos en curso de trabajo y fallas de fabricación}

Se destacan también claramente masas metálicas deformadas, barras y varillas. Estos objetos corresponden a esbozos en curso de trabajo o de fabricación del taller que atestiguan claramente una producción local. Hemos seleccionado primero dos masas metálicas. La primera 27-15 B.105 es de forma rectangular. Mide $28 \mathrm{~mm}$ de largo, entre 8 y $11 \mathrm{~mm}$ de ancho y tiene $5 \mathrm{~mm}$ de espesor, su masa es $3 \mathrm{~g}$. La segunda 27-30 B.68, con forma circular, tiene un diámetro de $15 \mathrm{~mm}$ y un grosor entre 3 y $5 \mathrm{~mm}$, su masa es $5 \mathrm{~g}$ (fig. 19).

La pieza de cobre 27-15 B.105, con azufre como impureza (0,2 \% en S) presenta una corrosión intergranular avanzada. El estado metalúrgico es bruto de fundición (fig. 20) con ligeras evidencias de recristalización en el borde derecho de la sección observada; la pieza ha sido ligeramente deformada y ligeramente recocida. Estas observaciones indican que el artesano empezó por deformar la pieza pero que no continuó el trabajo de deformación.

La pieza de forma circular 27-30 B.68 es de cobre no aleado muy «limpio» (100\% en $\mathrm{Cu}$ ); ha sido deformada para formar cuatros ángulos (fig. 19). El examen metalográfico muestra claramente que la superficie total de la pieza es 

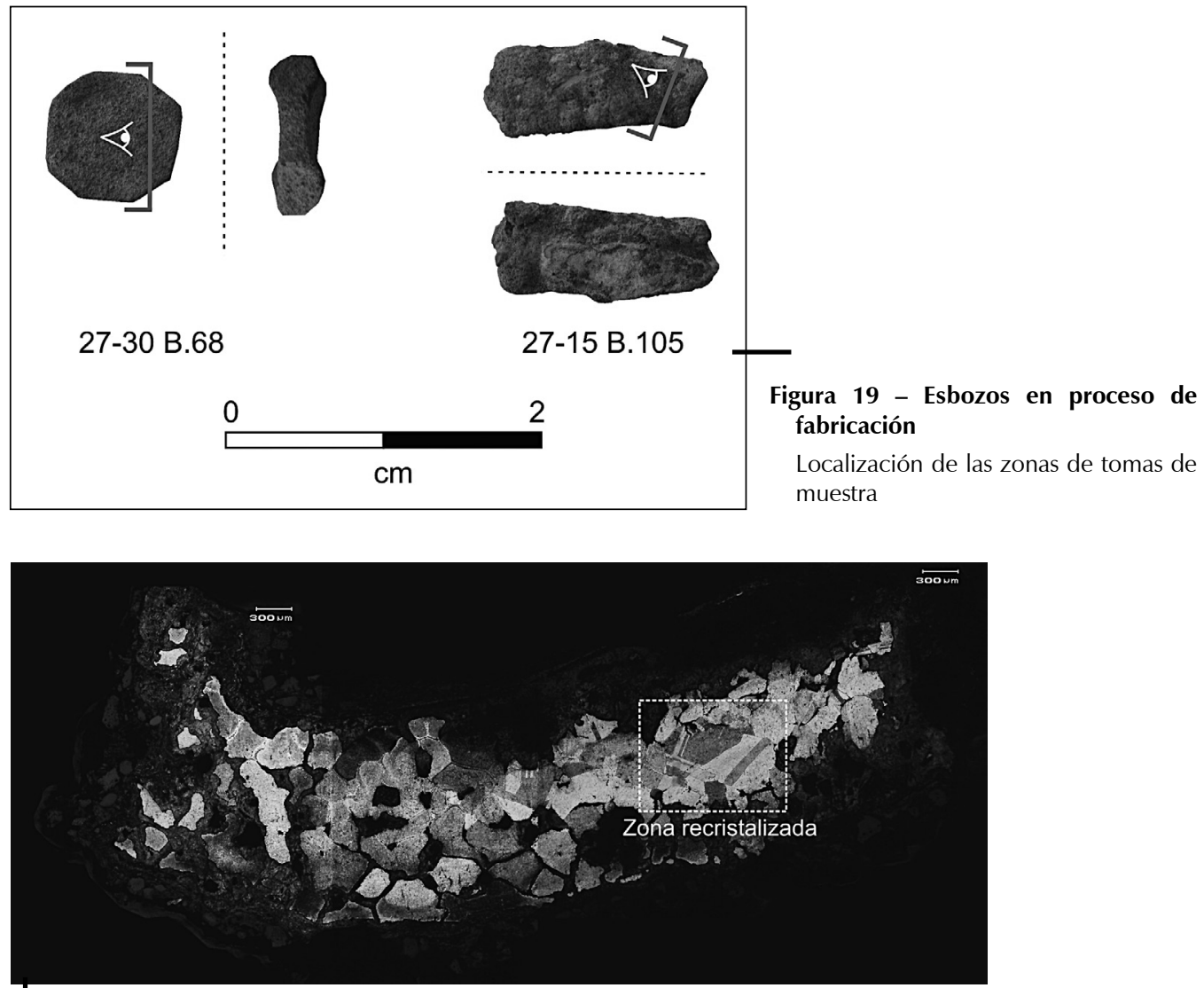

Figura 20 - Pieza esbozada 27-15 B.105

Observaciones metalográficas de la sección transversal pulida y atacada con una solución acida de percloruro férrico durante $30 \mathrm{~s}$. La superficie observada presenta un estado de corrosión intergranular avanzado. El estado metalúrgico presenta amplios granos dendríticos típicos de un estado bruto de fundición. La parte derecha de la imagen muestra una ligera zona recristalizada y amplios granos con maclas de recocido $(300 \mu \mathrm{m})$

en un estado final recristalizado (fig. 21). La pieza recibió uno o varios ciclos de martillado y recocidos sucesivos; el estado final es recocido.

Tres varillas observadas en sección pulidas completan nuestro examen (fig. 22). La primera, 27-30 B.62, es un fragmento de varilla con sección rectangular de $74 \mathrm{~mm}$ de largo y $3 \mathrm{~mm}$ de ancho, tiene $1 \mathrm{~mm}$ de espesor y su masa es $2 \mathrm{~g}$. El segundo objeto, 27-30 B.09, es una varilla con sección rectangular que mide 40 x 5 mm y presenta $2 \mathrm{~mm}$ de espesor, su masa es $1 \mathrm{~g}$; está ligeramente doblada. Finalmente, la varilla 27-15 B59, con sección cuadrangular, es un fragmento deformado. Mide $27 \times 4 \mathrm{~mm}$ con $3 \mathrm{~mm}$ de espesor y su masa es $1 \mathrm{~g}$.

Las varillas 27-30 B.09 y 27-15 B.59 están compuestas de cobre no aleado, otra vez muy «limpio» $(100 \%$ en $\mathrm{Cu}$ ). Las observaciones microscópicas revelan un 


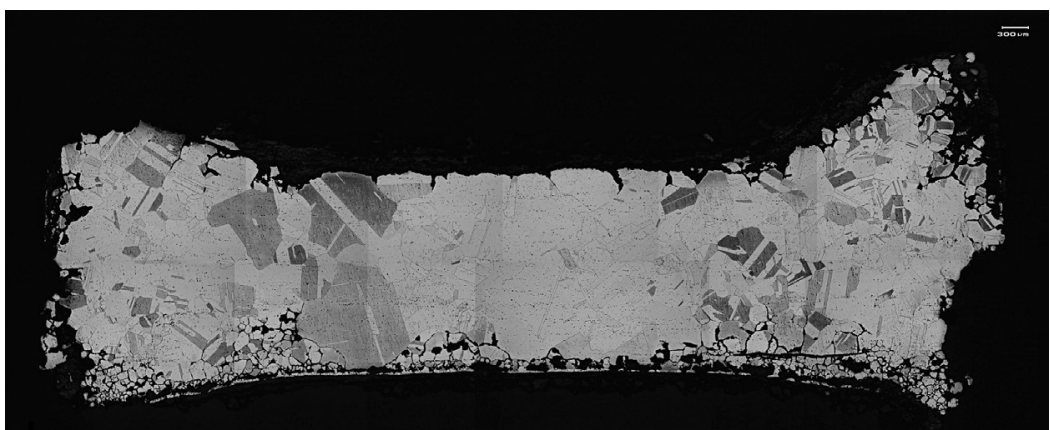

Figura 21 - Esbozo 27-30 B.68

Observación metalográfica de la sección transversal pulida y atacada con una solución acida de percloruro férrico durante 60 s (ampliación x5). La corrosión intergranular empieza desde los bordes de la pieza y progresa en el metal (en negro). El estado metalúrgico final es totalmente recristalizado, los granos presentan maclas de recocido de dimensiones variables, entre $100 \mu \mathrm{m}$ y $400 \mu \mathrm{m}$

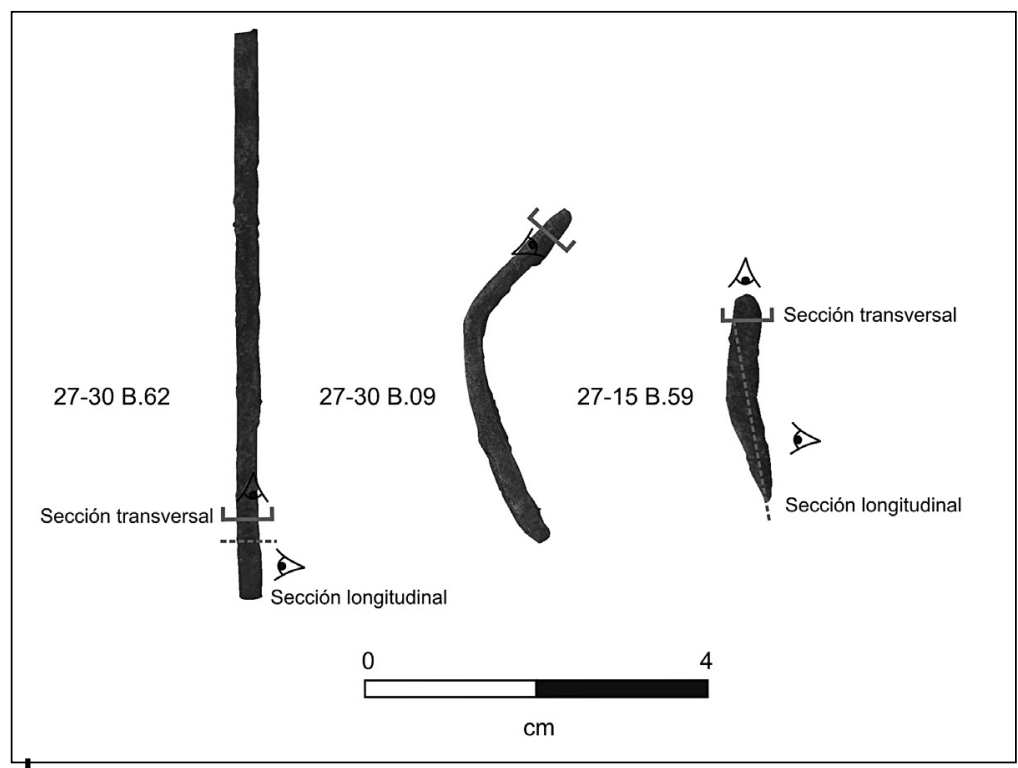

Figura 22 - Varillas en proceso de fabricación

Localización de las zonas de tomas de muestra. El fragmento de varilla 27-15

B.59 ha sido examinado en su totalidad

estado de corrosión avanzado al nivel de los bordes de cada muestra. Ambas presentan un estado metalúrgico totalmente recristalizado y pequeños granos con maclas de recocido, entre 10 y $60 \mu \mathrm{m}$ (fig. 23). Las piezas han recibido varios encadenamientos de deformación en asociación con recocidos de recristalización. La ausencia de líneas de deslizamiento indica que la última operación efectuada por el metalurgista ha sido un recocido en atmósfera, más o menos, oxidante, 


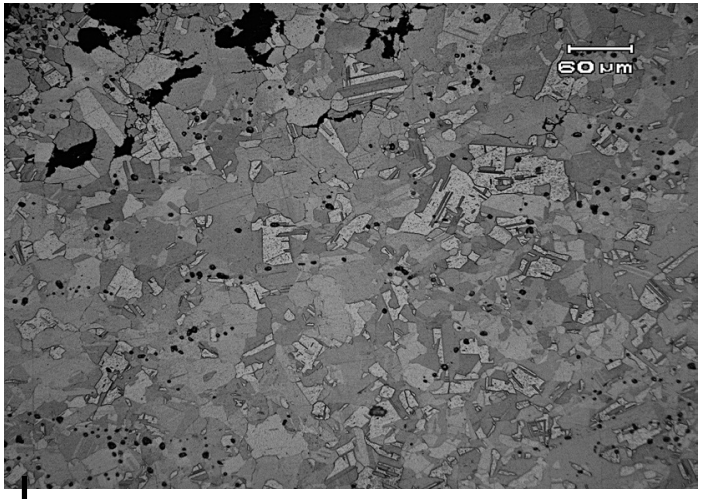

Figura 23 - Observación metalográfica de la sección transversal pulida y atacada con una solución acida de percloruro férrico durante $35 \mathrm{~s}$. (ampliación x50)

Varilla 27-15 B.59. Estado metalúrgico totalmente recristalizado con pequeños granos y maclas térmicas, entre 20 et $60 \mu \mathrm{m}$

seguramente aplicado para ablandar el metal con el fin de seguir su deformación con nuevas series de martillado. Estamos claramente en presencia de esbozos en proceso de fabricación que han sido abandonados en el taller.

Finalmente, la varilla 27-30 B.62, con sección rectangular, destaca notablemente de las dos precedentemente descritas: primero, por su composición química y luego, por su estado metalúrgico final. Se trata de una varilla en aleación ternaria intencional de $76 \%$ de cobre, 19,5\% de oro y 4,5 \% de plata. La observación en sección transversal, tras el ataque químico, reveló en primer lugar un estado metalúrgico final deformado con granos muy alargados así como la presencia de líneas de deslizamiento que subraya el alto grado de deformación recibido por la pieza (fig. 24). La aleación tiene algunos poros y el borde superior de la varilla muestra la progresión longitudinal de una fisura; el inicio de otra fisura, la cual progresa hacia el interior de la matriz, se observa abajo en la parte inferior de la varilla (fig. 25a).
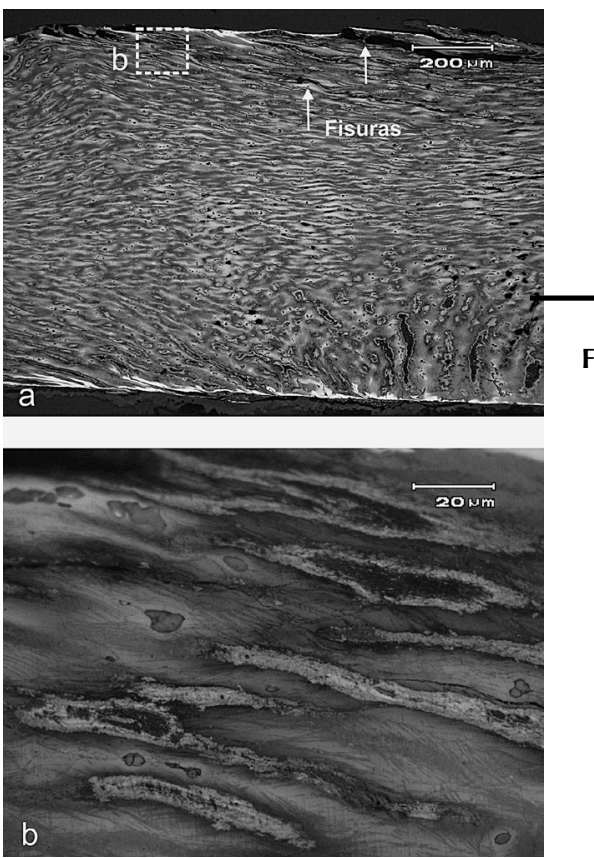

Figura 24 - Varilla 27-30 B.62

Observaciones metalográficas de las secciones transversales pulidas y atacadas con una solución acida de percloruro férrico durante $15 \mathrm{~s}$.

a: Aleación ternaria intencional con $76 \%$ de cobre, $19,5 \%$ de oro y $4,5 \%$ de plata

Se observa la presencia heterogénea de un metal precioso en las superficies, superior e inferior, de la pieza. En el borde superior, se puede distinguir la progresión de dos fisuras progresando hacia el interior de la matriz (ampliación x20)

\section{b: Estado metalúrgico final muy deformado}

Los granos son muy alargados y atravesados por líneas de deslizamiento que se caracterizan por la presencia de estrías (ampliación x100). 
Por otra parte, la observación en sección longitudinal de la varilla precisa los gestos llevados a cabo por el artesano. En efecto, el examen indica que la pieza recibió diversas grandes deformaciones por series de martillado alternadas en ambas caras; los bordes laterales no fueron deformados. La cara superior (fig. 25a) sufrió deformaciones más fuertes que se caracterizan por el alargamiento importante de los granos en esta zona específica (fig. 25b). Esta cara, más deformada, presenta igualmente una superficie muy irregular que se manifiesta al nivel de una fisura importante (fig. 25a). La cara inferior, menos deformada, estaba posicionada sobre el yunque. Estas observaciones prueban que estamos probablemente enfrentados a evidencias de un accidente de trabajo durante el proceso de deformación, es decir que el artesano no parece haber aplicado un recocido de recristalización en el momento adecuado. La continuación de la deformación por martillado
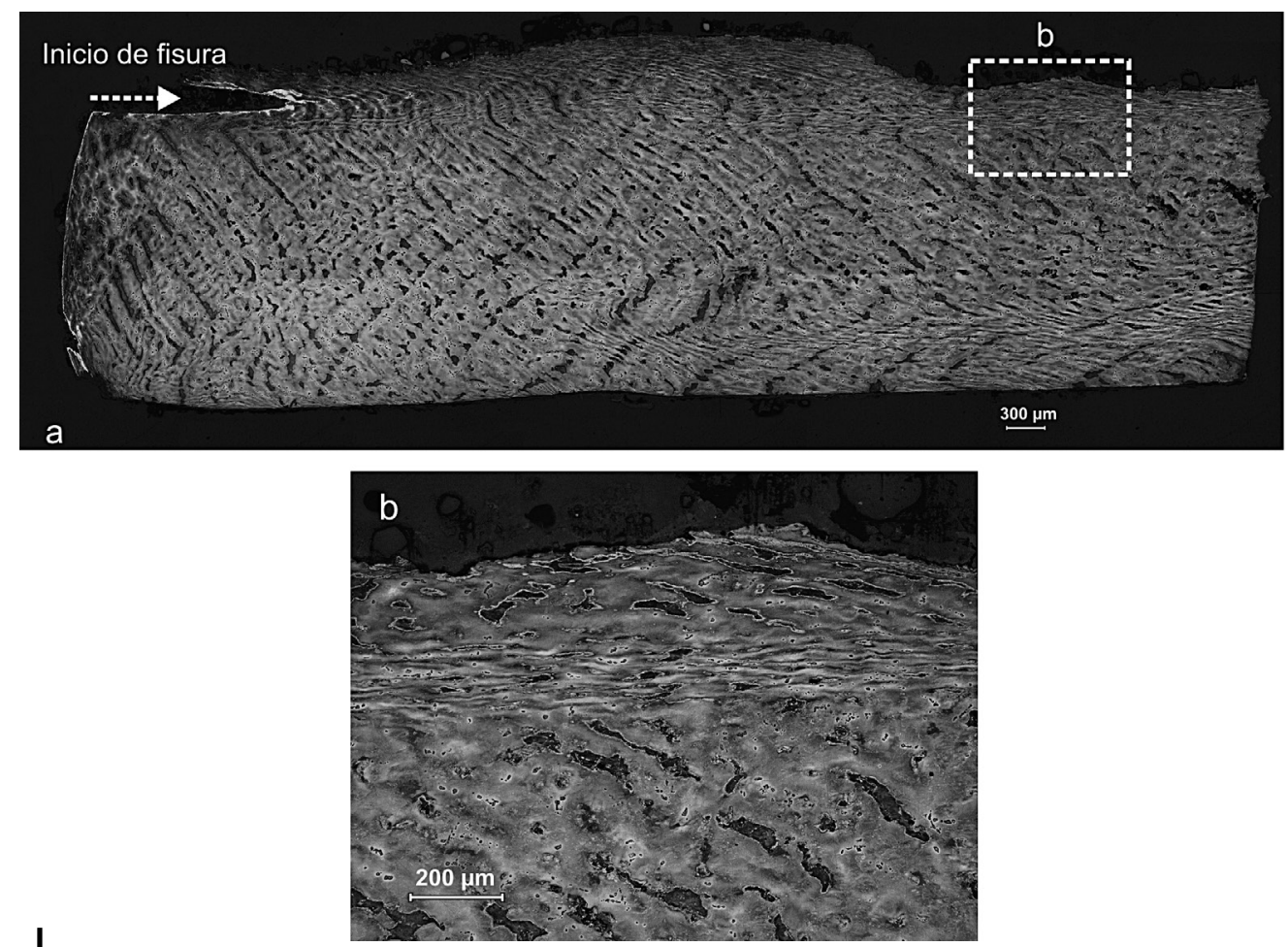

Figura 25 - Varilla 27-30 B.62

Observaciones metalográficas de la sección longitudinal pulida y atacada con una solución acida de percloruro férrico durante $15 \mathrm{~s}$.

a: Estado metalúrgico final muy deformado que se caracteriza por la orientación y la forma alargada de los granos y los poros (en negro)

La cara superior de la pieza recibió deformaciones más fuertes y muestra una superficie muy irregular consecuente al inicio de una fisura que provocó el paro inmediato del trabajo de la pieza (ampliación x5)

b: Detalle de la cara superior muy deformada. Los golpes de martillo han sido aplicados perpendicularmente a la superficie (ampliación x20) 
provocó la ruptura de la aleación, la cual se caracteriza por el inicio de una fisura irreversible y, consecuentemente, la interrupción inmediata del proceso de fabricación de la pieza.

En fin, las observaciones en secciones, transversal y longitudinal, revelaron la presencia de un metal precioso (oro y/o oro-plata) específicamente localizado, de manera muy irregular, en los bordes de la varilla (fig. 24a). Una segunda serie de análisis puntuales complementada por un análisis de concentración en perfil fueron efectuados con el fin de estudiar la formación de este enriquecimiento en oro y/o oro-plata en la superficie de la pieza (fig. 26). Los resultados revelan un neto enriquecimiento en oro al nivel de la superficie, en paralelo a la disminución respectiva del cobre (fig. 27). Este fenómeno es característico de la técnica de dorado por empobrecimiento de la superficie en cobre o depletion gilding.

Esta segunda serie de análisis y exámenes que confirma las observaciones metalográficas, prueba que estamos en presencia de una pieza claramente abandonada durante su fabricación a causa de error o accidente en el proceso. El proceso de dorado por empobrecimiento de la superficie en cobre, que se relaciona con la fabricación de piezas por martillado y tratamientos de recocido en sucesivos, no fue terminado.

Aunque sea imposible determinar la forma y la finalidad precisa de este conjunto de piezas es, sin embargo, posible concluir que operaciones de fundición de cobre y aleación (tumbaga) refinados se efectuaban en el taller. Luego, la cadena

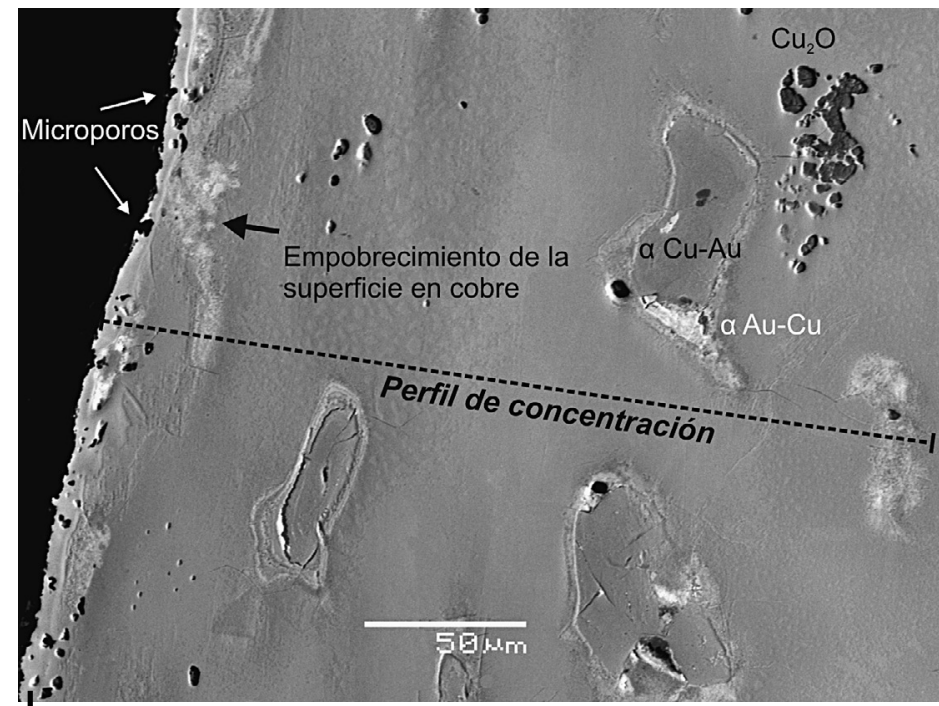

Figura 26 - Varilla 27-30 B.62

Observación en microscopia electrónica, en modos de electrones retrodispersados (ampliación x450), acoplado a un análisis de perfil de concentración EDXS. La sección pulida observada pone en evidencia la presencia heterogénea de un metal precioso específicamente localizado en las superficies de la pieza (en blanco) donde se observan microporos (en negro) 


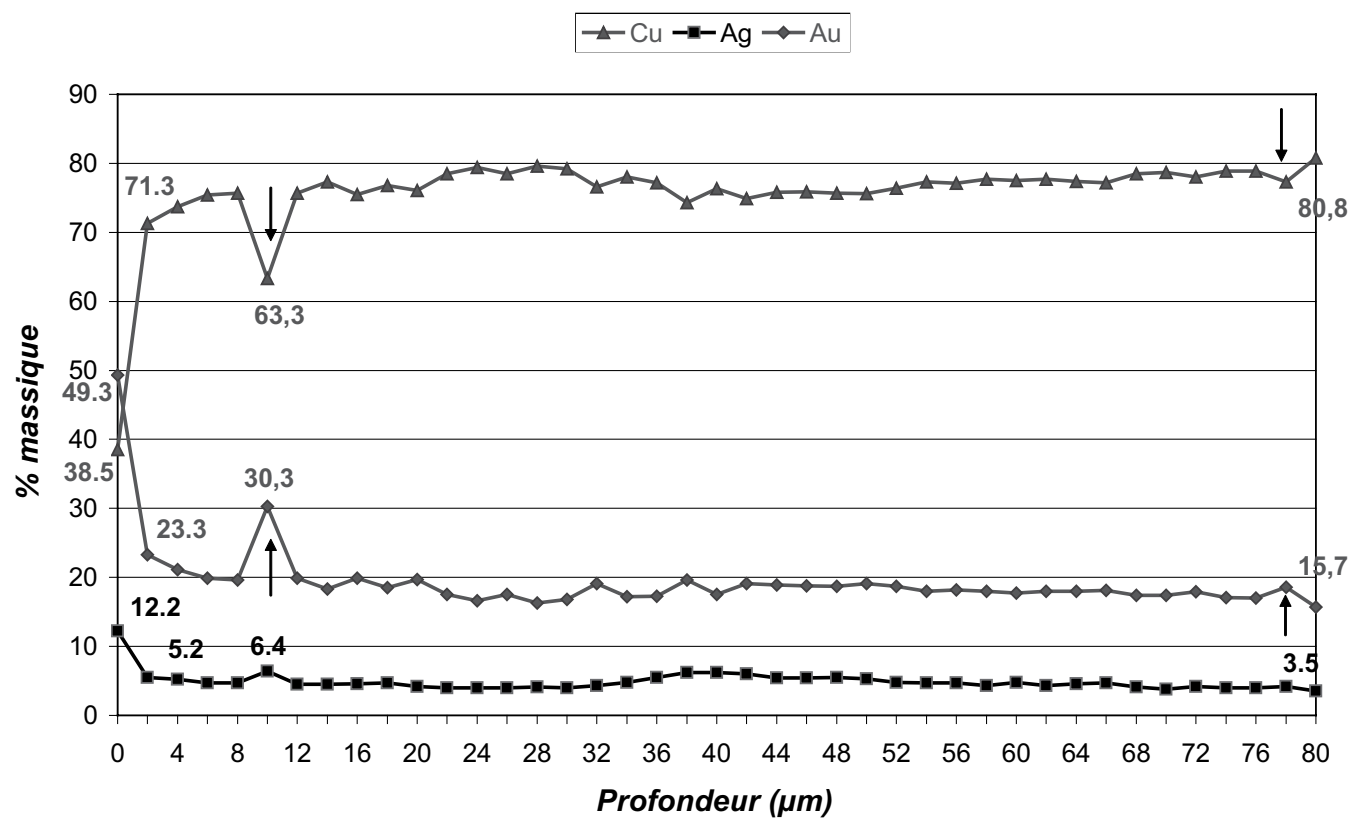

Figura 27 - Varilla 27-30 B.62

Perfil de concentración realizado a partir de 53 medidas, a $2 \mu \mathrm{m}$ de intervalo, desde la superficie hacia la matriz de la aleación. Los resultados muestran un enriquecimiento brusco del oro en la superficie y un empobrecimiento respectivo del cobre. El pico de oro observado a $10 \mu \mathrm{m}$ de profundidad de la superficie y asociado a la disminución neta del cobre, corresponde a un grano de oro. A partir de $6 \mu \mathrm{m}$ de profundidad de la superficie, el valor del oro empieza por aumentar en paralelo a la disminución progresiva del cobre. La plata tiene un porcentaje medio bastante constante; aumenta netamente a $2 \mu \mathrm{m}$ de distancia de la superficie en asociación con el oro; la plata siendo disuelta en el oro.

operativa seguía con operaciones de deformación plástica de pequeños objetos en asociaciones con tratamientos de recocido de recristalización.

\section{5. El material lítico}

Un total de 28 objetos líticos, asociados al piso y el relleno de ocupación de la capa 2, se registró en los espacios 27-15 y 27-30 (fig. 28). Pocos objetos han sido formados, es decir, que una forma precisa y destinada a un uso preciso, no ha sido dada (paralepípedos, cilindros, conos, etc.). Ciertas piedras presentan huellas de golpe, otras parecen estar en proceso de fabricación.

La mayoría de los estigmas identificados en los objetos resultan de impactos que destacaron esquillas. Otros tipos de huellas resultan de roces; se caracterizan por superficies lisas y planas. Los materiales empleados son rocas duras de origen magmática: andesita, granito y granodiorita (Chinguala et al., 2003: 125). 


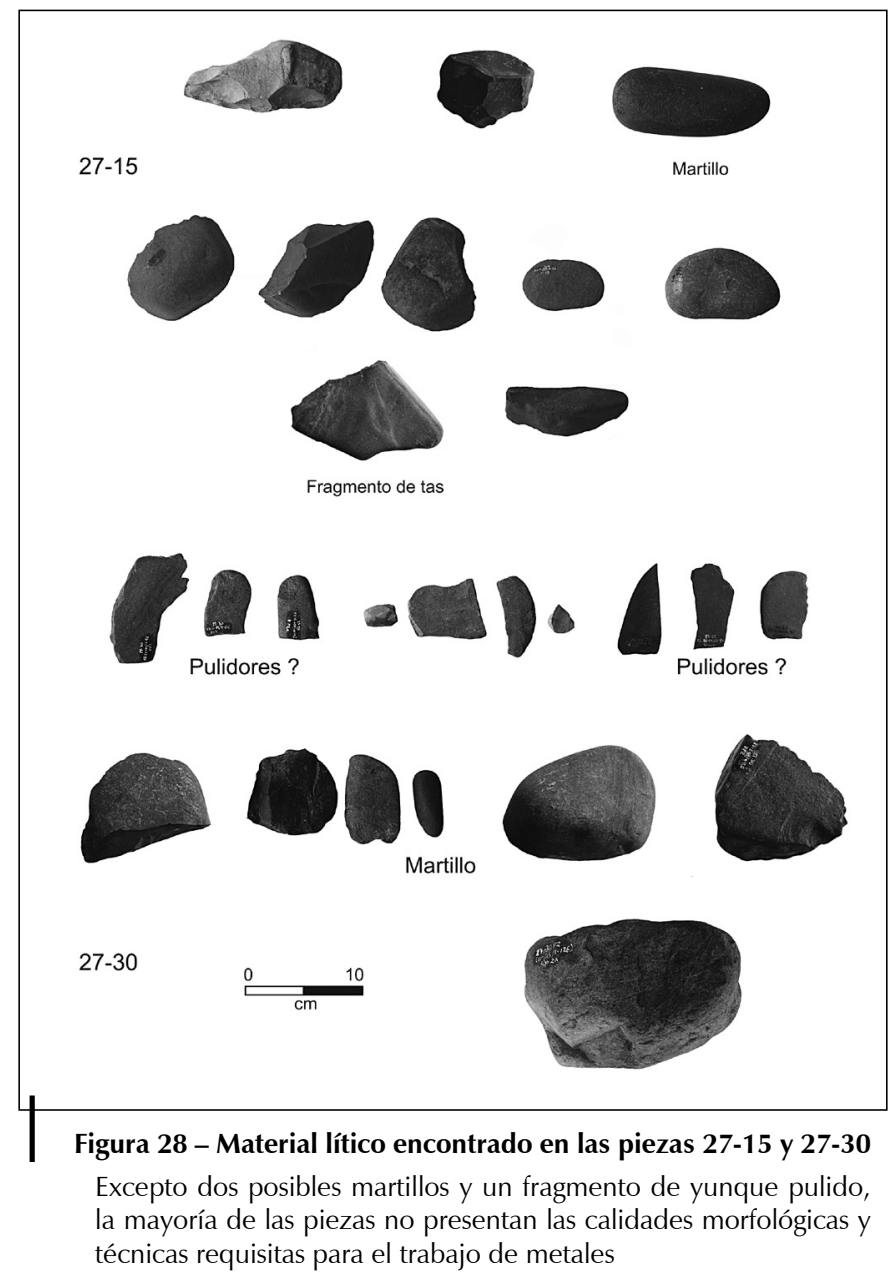

Entre este conjunto de material lítico, tres grandes categorías de herramientas se reconocen. La primera corresponde a herramientas «activas», es decir de golpe. Se componen de dos martillos pulidos con forma alargada, de los cuales una o las dos extremidades redondeadas presenta(n) huellas de impacto. Notamos que la mayoría de los objetos líticos encontrados en el subconjunto 3 está principalmente constituida por bloques irregulares con huellas de cascos evidentes; estos últimos no entran en la cadena operativa de fabricación de objetos de metal.

La segunda categoría de herramienta está representada por la presencia de un solo fragmento de tas (o pequeño yunque) cuya forma original formaba un paralelepípedo, de superficie plana y lisa.

Finalmente, la última categoría se compone de objetos planos y más o menos lisos, cuyas superficies presentan evidencias de frotamiento. Este tipo de piezas podría corresponder a pulidores; sin embargo, la morfología de estos últimos no 
responde a los criterios generalmente definidos para estas herramientas (Carcedo, 1992; 1998).

\section{CONCLUSIONES Y DISCUSIÓN}

Entre 600 y 700 d. C., los artesanos del taller metalúrgico CA-27 de la huaca de la Luna realizaban operaciones de fusión para refinar el cobre y preparar aleaciones tumbaga con el fin de obtener metales con propiedades adecuadas a la fabricación de pequeños objetos de cobre y cobre dorado por martillado. Remodelaciones indican que hubo dos fases continuas de funcionamiento en cada espacio; los espacios 27-15 y 27-30 fueron ampliados; sin embargo, es imposible precisar cuánto tiempo funcionaron.

\section{1. Taller de transformación: actividades de fundición y posfundición}

Algunas interrogantes quedan abiertas, particularmente a propósito de las estructuras de hornos y los tipos de moldes utilizados por los metalurgistas mochicas. Los hornos de fusión (fundición) y los hornos de recocido no son aún distinguidos con precisión. Las técnicas del vaciado (con moldes permanentes o de uso único, cera perdida, fundición en arena) para la fabricación de los esbozos o de las piezas tampoco son identificadas.

Las actividades de fundición están, por lo tanto, deducidas en el taller por la identificación y caracterización de fragmentos de crisoles, los restos de un horno de fusión circular de estructura simple, pequeñas toberas y también por la presencia de un pequeño lingote y dos esbozos de cobre no aleado remarcablemente limpio. Aunque ningún molde o fragmentos de moldes hayan sido encontrados, este tipo de «herramienta» fue necesariamente utilizada en el taller para la fabricación de los esbozos. Recordemos que los moldes de uso único (arcilla o arena) no dejaban vestigios materiales de manera obligatoria. Asimismo, el artesano puede deshacerse de los fragmentos tirándolos por otro lugar, después del desmolde. Por otro lado, los moldes permanentes no son abandonados por el artesano sino guardados cuidadosamente para futuros usos; y en ciertos casos hasta los acompaña, junto a otras herramientas, en su tumba (Carcedo \& Vetter, 2002; Fraresso, 2007). La ausencia de conos de alimentaciones13 puede explicarse, por otra parte, por la práctica del reciclado.

Las actividades de posfundición están relacionadas con una segunda categoría de vestigios: hornos o fogones simples de recocido, toberas, caídas y recortes de

13 Los conos de alimentación son los positivos del orifico de entrada por donde fue colado el metal en fusión. Generalmente, tras el desmolde, el cono de alimentación está cortado y reciclado, es decir refundido. 
láminas, fallas de fabricación durante el proceso de deformación plástica y huellas de limaduras que se manifiestan por la presencia de una mancha de sales de cobre oxidado sobre el suelo, sugiriendo la práctica de operaciones repetidas de pulido. El estudio tecnológico indica que operaciones de deformación eran realizadas en este espacio. Se traduce por la puesta en forma de varillas y/o tal vez láminas por series de operaciones de martillado y tratamientos térmicos de recocido en sucesivo para fabricar pequeños objetos, de los cuales ciertos de ellos presentarán un aspecto final dorado. En efecto, las observaciones de la varilla 27-30 B.62 prueba que la técnica del dorado por empobrecimiento de la superficie en cobre, la cual es inherente al proceso de deformación por martillado de aleaciones tumbaga, era utilizada, entre 600 y 700 d.C., en el taller del Núcleo Urbano de la huaca de la Luna. Conviene subrayar que ninguno de los vestigios está relacionado con operaciones de decoración, acabado, ensambladura o reparación.

Finalmente, es imposible precisar qué tipo(s) de pieza(s) u objeto(s) eran producidos en este taller. Los objetos acabados (espátula, punta y tumi en miniatura) que se registraron en la zona perturbada por la escorrentía del taller, no son de ninguna manera objetos discriminantes que permiten saber si fueron fabricados localmente o bien importados a este espacio. Es interesante constatar que nos encontramos en el mismo caso de figura que aquel del taller Mochica Tardío de Pampa Grande, para el cual Izumi Shimada señaló que era difícil saber si las últimas etapas de fabricación de las piezas eran realizadas en el taller o en otro lugar (Shimada, 1994; 2001). No conociendo lo(s) tipo(s) de objeto(s) producido(s) en estos talleres, cabe señalar lo siguiente:

- Primero, la fabricación de objetos vaciados o de ciertos tipos de piezas no implica necesariamente la realización de una decoración. En efecto, la cadena operativa de fabricación de ciertas piezas también puede terminar con una operación simple de pulido. Es también factible que la realización de las decoraciones y las operaciones de acabado de ciertos objetos de lujo, sean efectuadas por otro grupo de hombres cuyos conocimientos y competencias no serán iguales. El lugar exacto es sin embargo todavía difícil de determinar puesto que ningún taller especializado en este tipo de actividades es conocido.

- Hélène Bernier señala la presencia de cuatro categorías de herramientas líticas en el complejo arquitectural CA-37, localizado al sur del complejo CA-27 del Núcleo Urbano (fig. 1). Entre estas categorías de herramientas, dos de ellas podrían entrar en la cadena operativa de fabricación de piezas de metales por deformación (yunque y martillo). Según el trabajo de la autora, actividades relacionadas con la talla de piedras semipreciosas para la fabricación de adornos y mosaicos eran principalmente llevadas a cabo en el taller del complejo CA-37 (Bernier, 2005: 205-207). ¿Sugiere la presencia de herramientas características al oficio de orfebrería en el mismo sitio una coordinación estrecha del trabajo entre diferentes unidades de producción? ¿Ciertas operaciones de deformación específicas (embutido, doblado, repujado, etc.) efectuadas en la fabricación de ciertas categorías de objetos (p.e: orejeras circulares), pudieron haber sido realizadas en paralelo a la elaboración de su mosaico decorativo? No se descarta 
esta posibilidad técnicamente coherente. El orfebre y el «decorador» pueden juntar sus competencias respectivas en las diferentes fases de fabricación de un objeto sin que rechacemos la posibilidad de que estas dos actividades distintas puedan también ser realizadas por el mismo hombre o grupo de hombres.

\section{2. Discusión}

Los artesanos que trabajaban en el taller del Núcleo Urbano de la huaca de la Luna eran especializados en técnicas de fundición y de posfundición pero no necesariamente en el trabajo de un único metal. Los artesanos preparaban cobres bastante purificados, es decir que tienen las buenas calidades requeridas para el trabajo por deformación y aleaciones preciosas tipo tumbaga.

Los tipos de competencias pueden dividirse en dos especialidades: el «fundidor», quien puede estar, a la vez, a cargo de la fusión del cobre y operaciones de refinado así como de la preparación de las aleaciones y de las operaciones de vaciado; y el «batidor» quien dará forma a una parte del esbozo o a la totalidad de la pieza por operaciones de deformación: martillado y recocido alternados. La ausencia o presencia de un «decorador» en el taller es difícil de asegurar. Las operaciones de pulido pueden entonces ser realizadas al final de la cadena operativa, por el fundidor o el batidor.

A continuación, el estudio del taller metalúrgico 27-30 de la huaca de la Luna indica que no hay una fuerte separación espacial de las diferentes etapas de la cadena operativa; es decir que no parece existir propiamente dicho un taller de fundición, un taller de martillado o un taller de decoraciones y acabados, específicamente dedicados a una sola función tecnológica. Es interesante subrayar que este tipo de organización espacial se observa también en las descripciones del taller de Galindo, localizado en el mismo valle (Bawden, 1996) mientras que una división neta del espacio y de las actividades suelen aparecer en el taller Mochica Tardío de Pampa Grande, localizado más al norte, en el valle de Lambayeque (Shimada, 1994; 2001). ¿Existieron diferentes territorios técnicos regionales o locales? Es difícil responder a esta pregunta en el estado actual de nuestra investigación. Primero, porque ningún estudio aqueometalúrgico similar está disponible; y segundo, porque es aún imposible precisar si una categoría de producto, centrada en la manufactura de objetos específicos (como adornos, objetos ceremoniales, instrumentos de música, herramientas, etc.) pudo haber constituido la marca de una identidad productiva (Pernot, 2006: 15). Sin embargo, existen suficientes índices positivos para continuar en este camino de investigación.

Finalmente, las evidencias arqueológicas del Núcleo Urbano del sitio de la huaca de la Luna tienden a mostrar que un sistema de organización artesanal especializado, en el cual diferentes grupos y tal vez corporaciones, de carácter social y religioso, participaban en la representación del poder. En efecto, los diversos trabajos relativos a la organización de varios talleres especializados en actividades de producción diversificada (metalurgia, textil, talla de piedras semipreciosas, fabricación de cerámica fina, fabricación de chicha, etc.) tienden 
a definir un modelo de organización controlado de la producción por las clases dirigentes de esta capital (Chapdelaine, 1997; 2001; Uceda \& Armas, 1997; Rengifo \& Rojas, 2004; 2008; Uceda, 2004b; Bernier, 2005; 2008). A partir de estos diversos trabajos y su correlación con los resultados del estudio tecnológico del taller metalúrgico CA-27 dos hipótesis surgen.

- La primera sería que esta unidad de producción (constituida por los espacios 27-15 y 27-30), la cual no está restringida a una sola función operatoria, estaba a cargo de una sola «dirección»: los ocupantes del complejo residencial CA-27 por ejemplo (Uceda, 2004b).

- La segunda hipótesis sería que esta unidad fabricaba semiproductos (láminas por ejemplo) que eran luego transferidos a otro taller, donde operaciones de decoración, ensamblaje y acabado eran realizadas bajo control de «patrones» diferentes (Chardron-Picault \& Pernot, 1999: 201).

La cuestión de la «dirección» de las actividades artesanales en el sitio de la huaca de la Luna sigue delicada. Las diferentes actividades artesanales organizadas en la ciudad parecen haber sido controladas directamente para y por la élite dirigente de este importante centro ceremonial (Uceda, 2004a). Así, las unidades de producción, organizadas en barrios, dependían quizás de un patronato dirigido por ciertos miembros de la élite, los cuales eran probablemente especializados en un tipo de actividad y solucionaban las decisiones económicas (materiales, productos, cantidades, etc.). No obstante, la presencia de barrios artesanales y la permanencia de las actividades, entre 400 y 900 d. C. podrían igualmente reflejar un control de la producción bajo la forma de corporaciones o guildas de artesanos; es decir, de una producción asegurada por grupos de hombres que se reunían para señalar la potencia de su(s) organización(es) (Pernot, 1998b: 60). Estas hipótesis abren nuevos campos de reflexión sobre la sociedad Mochica, pero subrayan a la vez la necesidad de aportar conocimientos más precisos sobre el mundo artesanal mochica (organización, técnicas, producción) y sobre su evolución cronológica en un mismo lugar.

\section{Referencias citadas}

BAWDEN, G., 1996 - The Moche, 385 pp.; Oxford: Blackwell Publishers Ltd.

BERNIER, H., 2005 - Étude archéologique de la production artisanale au site Huacas de Moche, côte nord du Pérou; Montreal: Universidad de Montreal, Departamento de Antropología, Tesis de Doctorado.

BERNIER, H., 2008 - Especialización artesanal en el sitio Huacas de Moche: contextos de producción y función sociopolítica. In: Actas de la Primera Conferencia Internacional de Jóvenes Investigadores sobre la Sociedad Mochica (L. J. Castillo, H. Bernier, J. Rucabado \& G. Lockard, eds.): 33-51; Lima: IFEA, Pontificia Universidad Católica del Perú, Dumbarton Oaks, Museo Larco Herrera, 4 y 5 de agosto del 2004. 
Huacas de Moche: estudio arqueométrico de un taller de transformación de cobre

CANZIANI AMICO, J., 2003 - Estado y ciudad: revisión de la teoría sobre la sociedad Moche. In: Moche: Hacia el Final del Milenio, Tomo 2 (S. Uceda \& E. Mujica, eds.): 287-311; Lima: Universidad Nacional de Trujillo, Pontificia Universidad Católica del Perú. Actas del segundo coloquio sobre la Cultura Mochica, Trujillo, del 1 al 7 de agosto de 1999.

CARCEDO DE MUFARECH, P., 1998 - Instrumentos líticos y de metal utilizados en la manufactura de piezas metálicas conservadas en los museos. Boletín del Museo de Oro, $\mathbf{n} .^{\circ}$ 44-45: 241-270.

CARCEDO, P. \& VETTER PARODI, L., 2002 - Instrumentos utilizados para la fabricación de piezas de metal para el período Inca. Bassler-Archiv. Beiträge Zur Völ kerkunde, Band 50: 47-66; Varsovia.

CHAPDELAINE, C., 1997 - Le tissu urbain du site Moche : une cité péruvienne précolombienne. In: À l'ombre du Cerro Blanco, Nouvelles découvertes sur la culture Moche de la côte nord du Pérou (C. Chapdelaine, ed.): 11-81; Montreal: Universidad de Montreal, Département de Antropología. Les Cahiers d'Anthropologie, vol. 1.

CHAPDELAINE, C., 2001 - The growing power of a Moche urban class. In: Moche Art and Archaeology in Ancient Peru (J. Pillsbury, ed.): 69-87; Washington D.C.: Center for Advanced Studies in the Visual Arts. Studies in the History of Art 63, Symposium Papers XL, National Gallery of Art.

CHARDRON-PICAULT, P. \& PERNOT, M., 1999 - Un quartier antique d'artisanat métallurgique à Autun. Le site du lycée militaire (P. Chardron-Picault \& M. Pernot, eds.):178-201; París: Maison des Sciences de l'Homme. DAF n. ${ }^{\circ} 76$

CHIGUALA, J., GAMARRA, N., GAYOSO, H., PRIETO, O., RENGIFO, C. \& ROJAS, C., 2003 - Dinámica ocupacional del conjunto arquitectónico 27. Núcleo urbano del complejo arqueológico Huacas del Sol y de la Luna. In: Proyecto arqueológico Huaca de la Luna. Informe Técnico 2003: 80-147; Trujillo: Universidad Nacional de Trujillo.

FRARESSO, C., 2007 - L'usage du métal dans la parure et les rites de la culture Mochica (150-850 ap. J. -C.), Pérou, 596 pp.; Bordeos: Universidad Michel de MontaigneBordeaux 3, UMR5060-CNRS. Tésis de Doctorado, IRAMAT-CRP2A.

FRARESSO, C., 2008 - Sistema Técnico de la Metalurgia de Transformación en la Cultura Mochica, Nuevas Perspectivas. In: Actas de la Primera Conferencia Internacional de Jóvenes Investigadores sobre la Sociedad Mochica (L. J. Castillo, H. Bernier, J. Rucabado \& G. Lockard, eds.): 153-171; Lima: IFEA, Pontificia Universidad Católica del Perú.

LECHTMAN, H., 1973 - The gilding of metals in pre-Columbian Peru. In: Application of Science in Examination of Works of Art: 38-52; Boston: Proceedings of the seminar conducted by the Research Laboratory and the Museum of Fine Arts, September 7-16 of 1965.

LECHTMAN, H., 1984 - Les techniques des orfèvres précolombiens. Pour la Science, vol. 82: 88-98.

LECHTMAN, H., 1997 - Copper artifacts from Moche burials at Pacatnámu. In: The Pacatnámu papers. The Moche occupation, Tomo II (C. B. Donnan \& G. A. Cock eds.): 251-253; Los Angeles: UCLA Fowler Museum of Cultural History's Editions.

OBERWEILER, C., 2005 - La métallurgie du cuivre et du bronze dans le monde égéen du Bronze Ancien au début du Bronze Récent (IIle millénaire-début du lle millénaire) : les techniques de fonderie; París: Universidad Paris I-Sorbonne. Tesis de Doctorado de Tercer Ciclo. Prehistoria, Etnología, Antropología. 
PERNOT, M., 1994 - Archéométallurgie du formage : le martelage des alliages à base de cuivre à l'époque protohistorique. Premiers résultats. La Revue de la Métallurgie: 849-861; París: CIT/Science et Génie des Matériaux.

PERNOT, M., 1998a - Archéométallurgie de la transformation des alliages à base de cuivre. In: L'innovation technique au Moyen-Âge (P. Beck, ed.): 123-133; París: Errance. Actes du Vlème congrès international d'archéologie médiévale, 1-5 octobre 1996.

PERNOT, M., 1998b - L'organisation de l'atelier du bronzier. In: L'atelier du bronzier en Europe du XXe au VIII siècle avant notre ère. Tome II : Du minerai au métal, du métal à l'objet (C. Mordant, M. Pernot \& V. Rychner, eds.): 107-116; París: CTHS. Actes du colloque international Bronze'96, Neuchâtel et Dijon.

PERNOT, M., 1999 - La métallographie. In: À la recherche du métal perdu - Les nouvelles technologies dans la restauration des métaux archéologiques (H. Meyer-Roudet, ed.): 65-67; París: Musée archéologique du Val d'Oise, Errance.

PERNOT, M., 2002 - Mise en forme des alliages cuivreux et archéométallurgie. La Revue de la Métallurgie, Février: 97-112.

PERNOT, M., 2006 - La place de la technique dans les sociétés anciennes. In: Cahier d'Épistémé. Histoire et éthique des sciences et des techniques (P. Duris, ed.): 7-25; Bordeaux: Universidad de Bordeos 1, vol. 1. Laboratorio Épistémé (EA 2971).

PERNOT, M. \& HURTEL, L., 1987 - Caractérisation métallographique de tôles d'alliages base cuivre des époques Celtique et Gallo-Romaine. Bulletin de la Société Préhistorique Française, Tome 84 (8): 238-247.

QUEIXOLA, I., MENU, M. \& MOHEN, J.-P., 1987 - Creusets pour la fonte des alliages à base de cuivre du Bronze Final au Fort-Harrouard à Sorel Moussel (Eure-et-Loire). Bulletin de la Société de Préhistoire Française, vol. 84 (1): 23-31.

RENGIFO CHUNGA, C. \& ROJAS VEGA, C., 2004 - Especialistas y centros de producción en el complejo arqueológico Huacas de Moche: evidencias de un taller orfebre. In: Proyecto arqueológico Huaca de la Luna. Informe Técnico 2004: 355-377; Trujillo: Universidad Nacional de Trujillo. No publicado.

RENGIFO CHUNGA, C. \& ROJAS VEGA, C., 2008 - Talleres especializados en el Complejo Arqueológico Huacas de Moche: el carácter de los especialistas y su producción. In: Actas de la Primera Conferencia Internacional de Jóvenes Investigadores sobre la Sociedad Mochica (L. J. Castillo, H. Bernier, J. Rucabado \& G. Lockard, eds.): 325340; Lima: IFEA, Pontificia Universidad Católica del Perú, Dumbarton Oaks, Museo Larco Herrera, 4 y 5 de agosto del 2004.

SCOTT, D., 1991 - Metallography and microstructure of ancient and historic metals, 155 pp.; Los Angeles: The Getty Conservation Institute.

SHIMADA, I., 1994 - Pampa Grande and the Mochica Culture, 328 pp.; Austin: University of Texas Press.

SHIMADA, I., 2001 - Late Moche urban craft production: A first approximation. In: Moche Art and Archaeology in Ancient Peru (J. Pillsbury, ed.): 177-205; Washington D.C.: Center for Advanced Studies in the Visual Arts. Studies in the History of Art 63. Symposium Papers XL, National Gallery of Art.

TOPIC, J. R., 1990 - Craft production in the kingdom of Chimor. In: The northern dynasties: kingship and statecraft in Chimor (M. E. Moseley \& A. Cordy-Collins, eds.): 145176; Washington D.C.: Dumbarton Oaks Research Library and Collection.

UCEDA, S., 2004a - El complejo arquitectónico religioso Moche de la Huaca de la Luna: el templo de la Divinidad de las Montañas. In: Investigaciones en la Huaca de la Luna 1998-1999: 367-376; Trujillo: Facultad de Ciencias Sociales de la Universidad Nacional de La Libertad-Trujillo. 
Huacas de Moche: estudio arqueométrico de un taller de transformación de cobre

UCEDA, S., 2004b - Los de arriba y los de abajo: relaciones sociales, políticas y económicas entre el templo y los habitantes en el núcleo urbano Moche de las Huacas de Moche. In: Informe de las Investigaciones en la Huaca de la Luna 2004: 283-318; Trujillo: Rapport de fouilles soumis à I'Institut Nacional de la Culture - Pérou (INC). No publicado.

UCEDA, S. \& ARMAS, J., 1997 - Los talleres alfareros en el centro urbano Moche. In: Investigaciones en la Huaca de la Luna 1995 (S. Uceda, E. Mujica \& R. Morales, eds.): 93-104; Trujillo: Facultad de Ciencias Sociales de la Universidad Nacional de La Libertad-Trujillo.

VALENCIA ESPINOZA, A., 2001 - Barro. In: Cusco: barro, fuego, plata. Fundición artística (J. Torres della Pina, ed.): 33-60; Lima. 